\title{
Dynamical Evolutionary Psychology: Individual Decision Rules and Emergent Social Norms
}

\author{
Douglas T. Kenrick, Norman P. Li, and Jonathan Butner \\ Arizona State University
}

\begin{abstract}
A new theory integrating evolutionary and dynamical approaches is proposed. Following evolutionary models, psychological mechanisms are conceived as conditional decision rules designed to address fundamental problems confronted by human ancestors, with qualitatively different decision rules serving different problem domains and individual differences in decision rules as a function of adaptive and random variation. Following dynamical models, decision mechanisms within individuals are assumed to unfold in dynamic interplay with decision mechanisms of others in social networks. Decision mechanisms in different domains have different dynamic outcomes and lead to different sociospatial geometries. Three series of simulations examining trade-offs in cooperation and mating decisions illustrate how individual decision mechanisms and group dynamics mutually constrain one another, and offer insights about gene-culture interactions.
\end{abstract}

Evolutionary psychology and dynamical systems theory have both been proposed as antidotes to the theoretical fragmentation that long characterized the field of psychology. Evolutionary psychologists have proposed that isolated psychological research topics such as aggression, taste aversion, language acquisition, mate selection, and spatial cognition can be connected to research on cultural anthropology, ecology, zoology, genetics, and physiology via principles of modern Darwinian theory (e.g., Buss, 1995; Kenrick, 1994; Lumsden \& Wilson, 1981; Tooby \& Cosmides, 1992). Dynamical systems theorists have searched for even more fundamental principles: general rules capable of linking information processing in the human brain with processes found in economic markets, biological ecosystems, and worldwide weather patterns (Holland, 1998; Lewin, 1993; A. Nowak, Vallacher, Tesser, \& Borkowski, 2000; A. Nowak \& Vallacher, 1998; van Gelder, 1998; Waldrop, 1992).

Evolutionary psychologists and dynamical systems theorists have already made a number of useful contributions to the development of a conceptually integrated science. However, mainstream researchers in each field have yet to fully incorporate developments in the other (see, e.g., Buss, 1999; A. Nowak \& Vallacher, 1998). Building bridges between the two fields holds considerable promise: Research from each of these areas has demonstrated that microscopic analyses of particular behavioral domains or isolated processes, without attention to the broader picture, can seduce researchers into accepting incomplete, and sometimes incorrect, explanations. Standing back to take a broad

Douglas T. Kenrick, Norman P. Li, and Jonathan Butner, Department of Psychology, Arizona State University.

Jonathan Butner is now at the Department of Psychology, University of Utah.

We thank Nia Amazeen, Steve Neuberg, Mark Schaller, Jeff Simpson, and Guy VanOrden for their insightful comments and suggestions.

Correspondence concerning this article should be addressed to Douglas T. Kenrick, Department of Psychology, Arizona State University, Tempe, Arizona 85287-1104. interdisciplinary perspective, on the other hand, often reveals elegant and parsimonious regularities not visible at the usual narrow focal range.

In this article, we argue that a focus on the contents of individual psychological decision-making mechanisms - the traditional domain of an evolutionary approach — can have important implications for social dynamics. At the same time, explicit consideration of dynamical processes can profitably expand the evolutionary perspective on organism-environment interactions. The general propositions of the dynamical evolutionary model we present are as follows:

1. Human psychological mechanisms can be conceived as a set of adaptive decision rules.

2. Those decision rules embody conditional strategies designed to serve fundamental motivations associated with key problem areas regularly confronted by our human ancestors.

3. Qualitatively different decision rules are associated with different problem domains.

4. Individuals will differ in decision rules as a function of adaptive design and random variations in trade-offs.

5. Decision mechanisms within any given individual unfold in dynamic interplay with the decision mechanisms of others in his or her social network.

6. Decision mechanisms in different domains have different dynamic implications, and sometimes lead to very different sociospatial geometries.

Propositions 1-4 follow from work in evolutionary psychology, and Proposition 5 follows from work in dynamical psychology. Proposition 6 follows from the integration of the two perspectives and has manifold implications for thinking about different areas of psychology and the social sciences.

In what follows, we first briefly overview some key assumptions of the evolutionary and dynamical approaches. We then present a broad framework for considering how decision rules relevant to different adaptive problem domains can lead to diverse emergent properties at the systems level. To illustrate the utility of thinking in dynamical evolutionary terms, we present two series of dynam- 
ical simulations based on existing assumptions and data from evolutionary psychology. One of these explores the effects of individual differences on trade-offs between conflict and cooperation in dynamical networks. The other explores dynamical implications of sex differences for mating decisions. We finally return to a discussion of the broader implications of a dynamical evolutionary approach to psychology.

\section{Evolutionary Psychology and Adaptive Computational Mechanisms}

Evolutionary psychology is a synthesis of developments in several different fields, with central themes deriving from work in ethology, cognitive psychology, evolutionary biology, and anthropology, as well as tributaries from animal learning; and social, developmental, and environmental psychology (Buss, 1999; Cosmides, Tooby, \& Barkow, 1992; Pinker, 1997; Shepard, 1992; Sherry \& Schacter, 1987). At the most general level, evolutionary psychology can be defined as the study of cognitive, affective, and behavioral mechanisms as solutions to recurrent adaptive problems (Cosmides et al., 1992; Crawford, 1998).

Darwin's theory of evolution by natural selection explained how recurrent environmental problems could shape physical traits. Seals are more closely related to dogs than to dolphins, but seals and dolphins share several morphological features shaped by common problems of aquatic life (where fins and streamlined body shape can assist in catching one's dinner and reduce the chance of becoming dinner for an aquatic predator). Along with the morphological features designed by natural selection, organisms also inherit central nervous systems capable of generating the behaviors necessary to run those bodies. The behavioral inclinations of a bat would not work well in the body of a dolphin or a giraffe and vice versa.

Zoologists and comparative psychologists have uncovered a wealth of behavioral mechanisms peculiarly suited to the demands of particular species (Alcock, 1998a). Some involve innate sensory and perceptual capacities. For example, dogs use smell for hunting; consequently, they have many more olfactory receptors than humans and are thousands of times more sensitive to various odors (Agosta, 1992). Humans, on the other hand, can see in color whereas dogs cannot (color vision may be useful for detecting ripe fruit, not part of a dog's diet). Bats, who hunt their food after dark, have echolocation capacities that allow them to construct the mental equivalent of a sonogram of the night world through which they must navigate at rapid speeds (Griffin, 1958).

Besides such "wired-in" differences in sensory and perceptual capacities, natural selection has favored many open-ended learning and memory biases fitted to species' ecological tasks. For example, rats, who have poor vision and rely on taste and smell to find food at night, easily condition aversions to novel tastes but not to visual stimuli (Garcia \& Koelling, 1966). Quail, on the other hand, who have excellent vision and rely on visual cues in food choice, show the opposite learning bias (Wilcoxon, Dragoin, \& Kral, 1971).

A key insight of the modern evolutionary perspective is that animals are not designed to be fitness-maximizing machines that can somehow foretell the adaptive consequences of future behaviors (Symons, 1992; Tooby \& Cosmides, 1992). Instead, evolutionary theorists view organisms as adaptation executors, com- posed of computational mechanisms designed by past adaptive demands. Thus, organisms are selected to seek goals such as "drink when thirsty," "protect your offspring," and "avoid foods that made you sick earlier," rather than "maximize your fitness" or "raise a maximum number of offspring to reproductive age."

Adaptive pressures are assumed to shape specific computational mechanisms designed to solve specific problems faced by an animal's ancestors (Tooby \& Cosmides, 1992). For example, birds use different memory systems and different rules for remembering species song, experiences with aversive food, and locations of food caches (Sherry \& Schacter, 1987). Species song is learned passively during a brief critical period, often without modeling or practice, yet it is perfectly reproduced during the next breeding season. Characteristics of poisonous foods, on the other hand, are learned in a single trial during any time of an animal's life, and are highly resistant to unlearning (cf. Garcia \& Koelling, 1966). Following yet a different set of rules, locations of food caches are learned, updated, and erased on a daily basis. As Sherry and Schacter (1987) pointed out, using the same decision rules for each of these problems would be highly inefficient, and different memory systems in birds are anatomically distinct. Humans similarly have different memory systems for dealing with different, sometimes conceptually incompatible, tasks, including language learning, food aversion, facial memory, and spatial location (Sherry and Schacter, 1987).

Thus, an evolutionary approach to behavior involves an analysis of particular recurrent problems faced by the members of a given species and a search across species for correlations between common behaviors and common environmental conditions (Alcock, 1998b). Rather than merely cataloging adaptations, the aim is to uncover common principles underlying these diverse adaptations. For example, the concept of differential parental investment ties together diverse findings from a wide range of species (Trivers, 1972). Briefly, as animals invest more in their offspring, they become more selective about mating decisions. As a consequence of selectivity in one sex, members of the opposite sex must compete for mating opportunities. This theory helps explain why male vertebrates are often more competitive, larger, or more colorful-because females generally make a higher investment in offspring (in mammals, for example, this involves internal gestation and nursing). In species with steep polygyny, as in elephant seals, males may be several times the size of females and considerably more aggressive (Haley, Deutsch, \& LeBoeuf, 1994). In species where both sexes share in raising offspring, as in swans and penguins, the sexes tend to be less differentiated (Daly \& Wilson, 1983). The theory explains seeming "sex-role reversals," as in phalaropes-birds in which females are more colorful and more competitive. Male phalaropes care for the eggs while females seek additional mates; hence, males are relatively more selective in choosing mates. Parental investment is one of a family of interrelated concepts (along with sexual selection, inclusive fitness, and kin selection) that have been linked together in a broad network of empirical findings from a wide array of animal species (see Figure 1).

Parental investment theory is one of a number of mid-range theories that flow from the broader theory of inclusive fitness. The fundamental assumption underlying inclusive fitness theory is that natural selection favored animals with traits that led to behaviors favoring replication of their genes in their own offspring and other relatives. Kin selection theory is another mid-range theory that 


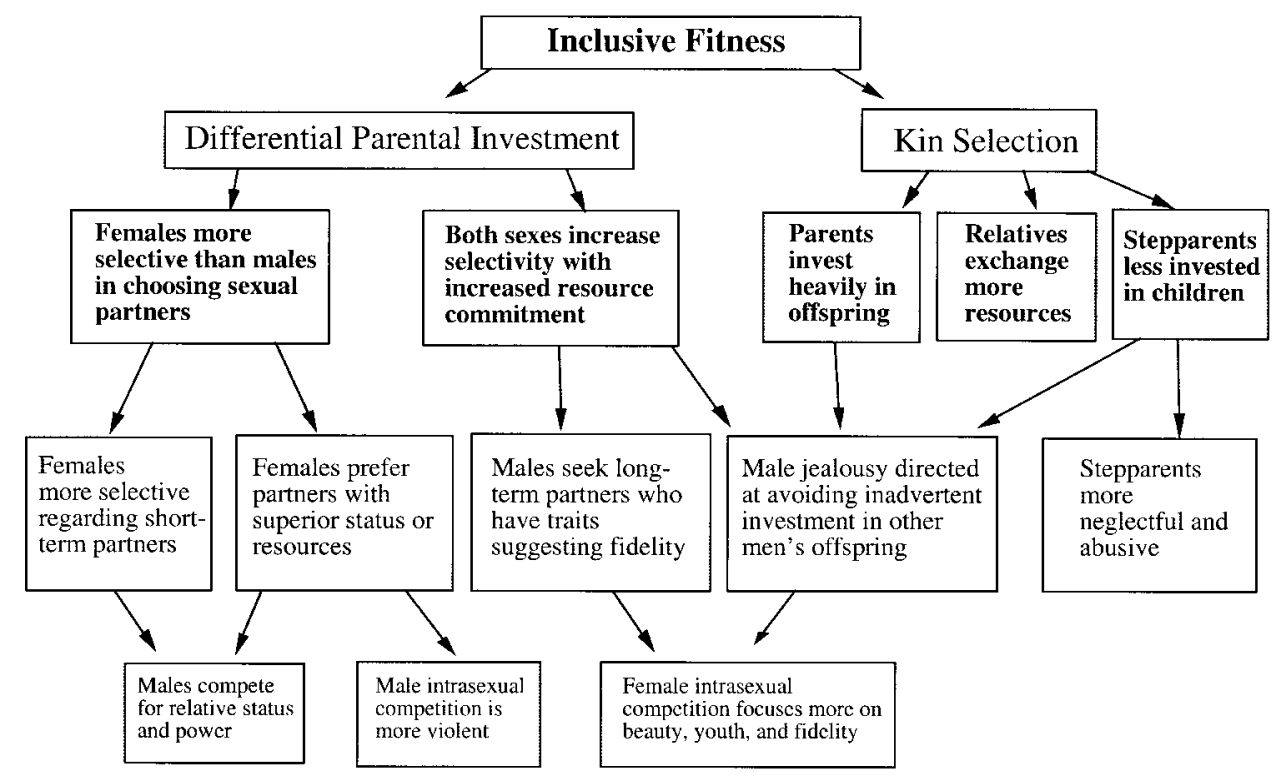

Figure 1. Patterns of social behavior across a wide range of animal species and human cultures may be linked via broad evolutionary principles.

follows directly from inclusive fitness theory and that generates a number of additional hypotheses about social behavior.

Evolutionary theorists have suggested benefits to conducting psychological research in light of biological findings on the broad diversity of animal species and anthropological findings on the broad diversity of human societies. For psychologists, however, this is not a call to abandon experimental studies of ongoing attention, perception, decision making, and social behavior. Rather, the presumption is that models of what humans think, feel, and do in any particular here and now might be better understood by learning as much as possible about the broader comparative context of ancestral humans, other primates, other social mammals, bird species with male parental investment, and so on (Crawford, 1998; Kenrick, 1994; Tooby \& Cosmides, 1992).

\section{Dynamical Systems and Self-Organization}

Dynamical systems theory, sometimes known as complexity theory, is, like evolutionary psychology, a cross-disciplinary venture. Its roots lie in computer science, ecology, mathematics, and physics, and its implications have been explored in fields as diverse as economics, genetics, and social psychology (Lewin, 1993; A. Nowak \& Vallacher, 1998; Waldrop, 1992). Generally, dynamical systems theory is concerned with the study of complex multicomponent systems (ranging from the microscopic-genes within the developing organism or networks of neurons within the brain - to the macroscopic - animals and plants within a particular Sequoia grove, or the millions of consumers within the North American economic market).

The dynamical approach focuses on changes over time rather than temporally isolated system states (A. Nowak \& Vallacher, 1998) and also emphasizes the ubiquity of nonlinear processes. A key feature of many dynamical systems is bidirectional causality. In a laboratory, an animal may be given a distinct and uncon- founded choice between two carefully controlled types of food. In a natural ecosystem, the food may take steps to avoid being eaten, or even bite back. Dynamical-systems theorists believe that studying bidirectional causality, though more difficult than studying isolated variables, is essential to understanding many natural phenomena. Observations across a wide variety of complex dynamic systems have yielded a pair of critical insights. First, great apparent complexity can arise spontaneously from the interaction of just a few simple parameters. Second, self-organization often arises out of initially random interactions of dynamically linked components (A. Nowak \& Vallacher, 1998).

Self-organization refers to the spontaneous emergence of new structures and patterns of behavior that were not programmed into the system but that have arisen from the combined activity of multiple components following simple rules. Such self-organization has often been demonstrated using cellular automatasystems in which a number of discrete elements are arranged in a spatial pattern. The elementary cells interact with their neighbors according to updating rules, such that the state of any element at a given point in time is determined by the state of its neighbors at the preceding point in time (Wolfram, 1986). Interactions between cells acting on simple rules (such as "follow the majority of your neighbors") often lead to the emergence of global patterns that were not programmed into the elements (Latané, 1996; A. Nowak et al., 2000). In this article, we specifically explore how such cellular automata can be used to examine the group-level implications of content-specific computational mechanisms posited by evolutionary psychologists.

Several key concepts are important to the discussion that follows. One is the concept of an attractor state, or an equilibrium point toward which a system is drawn. A familiar example from the field of social psychology comes from research on replenishing resource dilemmas, in which a group of individuals share a com- 
mon resource that replenishes at a rate that depends on the remaining amount of the resource (Schroeder, 1995). A typical outcome is that the whole group greedily consumes the resource as soon as any one individual begins to take more than his or her share, leading the group to fall rapidly toward a stable equilibrium in which the resource is completely depleted (Brechner, 1977).

Another important concept is the idea of a control parameter, or an external variable influencing the behavior of a system (such as whether group members sharing common resources can communicate with one another or not; Neidert \& Linder, 1990). Some such external factors cause qualitative shifts in the behavior of the system, called phase transitions. The particular values at which the system changes its general behavior are called bifurcation points. At some parameter values, a system may be unimodal, or drawn toward only one attractor state regardless of other conditions (as when a group of noncommunicating strangers in a commons dilemma observe decreases in a limited pool of shared resources and deplete the remaining resources in a panic of self-interest). At other parameter values, a system may be multistable - that is, it may be drawn toward different attractor states depending on random factors and the values of other parameters (a dyad in a prisoner's dilemma may settle into a prolonged pattern of cooperation or conflict depending on initial moves by either player). In such multistable systems, random variations in initial conditions are critical. According to A. Nowak and Vallacher (1998), identifying the control parameters that produce such qualitative changes is a critical step in understanding any dynamical system.

The dynamical perspective has focused more on common patterns that emerge across very different kinds of systems than on the particulars of any given type of system. The locally important control parameters in a system are often inferred from empirical observation of the system in operation, using mathematical tools to help simplify the system's behavior (A. Nowak \& Vallacher, 1998). Dynamical approaches thus share with traditional cognitive psychology an emphasis on content-independent processes (Gardner, 1985; Glass \& Holyoak, 1986). This content-independent approach has limitations in providing direction with regard to the questions "What are the particular kinds of information that provide the crucial inputs for decisions made by living organisms?" and "What are the decision rules by which different types of informational inputs are transformed into behavioral outputs?"

Latané and colleagues have proposed that there are different "geometries of social space" within which dynamic social influence occurs (Latané \& Liu, 1996; Latané \& Bourgeois, 1996). For example, in a family geometry a small number of people interact extensively with one another, with individualized links to other families. On the other hand, people living along a river (as many of our ancestors did) interact with neighbors to their immediate left and right in what Latané and Bourgeois called a "ribbon geometry" (Latané \& Bourgeois, 1996). In their "torus geometry" (Latané \& Bourgeois, 1996), people interact with immediate neighbors to the north, south, east, and west (analogous to people living within a village). Latané and Liu (1996) noted that the shape of social space is influenced by human motives but did not explore the implications of this suggestion, focusing mainly on constraints of physical space. Below, we suggest that a consideration of biological as well as physical constraints has profound implications for the geometry of social dynamics.

\section{A Content-Based Framework for a Dynamical Evolutionary Psychology}

Dynamical approaches have modeled human social interactions using simulations in which discrete spatially arranged elements interact with their neighbors according to updating rules-weighting schemes for evaluating inputs from neighbors. But what are the updating rules actual humans use to make decisions in response to their neighbors' behaviors? And which behaviors emitted by which neighbors will affect particular behavioral decisions? In real social networks, people do not pay attention to every single informational input from every other group member.

A fundamental tenet of modern cognitive psychology is that attention and memory are selective (Martindale, 1991). At any given moment, a wide spectrum of inputs stimulates thousands of sensory neurons in diverse ways. We cannot attend to every form and instance of environment stimulation, and we cannot consciously consider every stimulus that does manage to register in sensory memory. Of the select inputs that do make it into the active processing register of consciousness, we cannot store each one in long-term memory nor can we later access every potentially relevant memory when we encounter a new situation. Hence, sensation, attention, conscious processing, and memory are all highly selective. Although it is possible to activate schemas for selective attention to vowels versus consonants, Ralph Lauren versus Izod icons, or Boston versus Philadelphia accents, there is evidence that unrestrained thought processes involve a set of default priorities. For example, social cognition researchers have observed that experimental subjects seem to spontaneously process characteristics such as gender, age, and attractiveness (Brewer \& Lui, 1989; Hastie \& Park, 1986). These findings suggest that information processing is selectively selective: Some categories of information are more likely to activate processing.

Which categories of information are likely to activate decisionoriented processing, and how might the decision rules, and resulting dynamics, differ by category? Comparative and evolutionary research has provided some suggestions of distinct neurophysiological systems underlying adaptive behavioral responses to major classes of adaptive challenges (e.g., Bugental, 2000; Panksepp, 1982; Plutchik, 1980; Scott, 1980). Recently, Bugental (2000) suggested distinct neurohormonal systems in humans designed to deal with problems in five domains of social development. These domains were labeled attachment (for safety maintenance), coalitional group (for acquiring and defending shared resources and territory), mating (for selecting and maintaining access to high value mates), reciprocity (for maximizing joint outcomes among equals), and hierarchical power (for optimizing balance between those of unequal power). Bugental's list overlaps reasonably well with a set of fundamental social goals suggested by Kenrick, Neuberg, and Cialdini's (2002) overview of research from the field of social psychology. The latter list included establishing social ties, gaining and maintaining status, defending ourselves and those we value, and attracting and retaining mates (as well as understanding ourselves and others, which could be seen as subserving the others). The goals of attracting and retaining mates are collapsed in both these schemes. However, they are worth considering separately, because each involves unique adaptive problems, as does the goal of caring for any resultant offspring (Buss, 1999). 
These functional analyses of the goals associated with different social domains provide one of the bases of the dynamical evolutionary model presented here. Table 1 overviews key hypothesized domains of social interaction and the fundamental goals associated with each domain. The table offers selected examples of likely decision constraints that have been hypothesized by evolutionary psychologists and the broad evolutionary principle on which that hypothesized decision constraint is based. Figure 2 suggests that each of those decision rules is associated with a somewhat different network geometry within which social dynamics are likely to unfold (integrating different perspectives from Latané \& Bourgeois, 1996; Bugental, 2000). Other examples could be offered, and one could bicker with the taxonomy of problem domains, but we believe this framework provides a fruitful way to open up questions at the interface of evolutionary and dynamical approaches. We now briefly consider the rationale for the hypothesized decision constraints listed in Table 1 and the associated network geometry described in Figure 2.

\section{Coalition Formation}

The adaptive functions of establishing friendships and participating in cooperative alliances have been discussed by numerous authors (Baumeister \& Leary, 1995; Stevens \& Fiske, 1995). Modern humans' hunter-gatherer ancestors lived in groups, as did most of the primates from which they evolved (Lancaster, 1976). Studies of modern hunter-gatherers have indicated that food sharing within such groups provided an essential insurance policy for survival through spotty times (Hill \& Hurtado, 1996). However, not all group members were equally friendly, and not all resources were shared all the time (e.g., Hill \& Hurtado, 1993). In making decisions about sharing resources, several types of informational input would have been critical. Evolutionary models have focused on the central importance of kinship and of the past history of exchange (e.g., Hamilton, 1964a, 1964b; Trivers, 1971). In line with inclusive fitness theory, research with humans and other species has suggested lower thresholds for engaging in cooperative behavior between neighbors who are closely related (e.g., Burnstein, Crandall, \& Kitayama, 1994; Essock-Vitale \& McGuire, 1985; Sherman, 1981). Helping is less linked to past history of reciprocation among close kin, but sharing between progressively less related individuals becomes more contingent on a history of reciprocal sharing (e.g., Fiske, 1992; Trivers, 1971; Wilkinson, 1988, 1990).

As depicted in Figure 2, a plausible network geometry for coalitional sharing among humans consists of clusters of closely related individuals with selective ties to individuals in other families (for example, a teenager in one family will have friendships with some cousins and with unrelated individuals who may or may

Table 1

Domains of Adaptive Problems, Fundamental Goals Associated With Each Domain, Examples of Evolved Decision Constraints, and Evolutionary Principles Underlying Decision Constraint

\begin{tabular}{|c|c|c|c|}
\hline $\begin{array}{l}\text { Social problem } \\
\text { domain }\end{array}$ & Fundamental goal & $\begin{array}{c}\text { Evolved } \\
\text { decision constraint }\end{array}$ & $\begin{array}{l}\text { Underlying } \\
\text { general principle }\end{array}$ \\
\hline $\begin{array}{l}\text { Coalition } \\
\text { formation }\end{array}$ & $\begin{array}{l}\text { To form and maintain } \\
\text { cooperative alliances }\end{array}$ & $\begin{array}{l}\text { Cooperation is more likely to the } \\
\text { extent that others (a) share } \\
\text { genes and (b) have shared } \\
\text { resources in past. }\end{array}$ & $\begin{array}{l}\text { Inclusive fitness } \\
\text { Reciprocal altruism }\end{array}$ \\
\hline Status & $\begin{array}{l}\text { To gain or maintain respect } \\
\text { from, and power over, } \\
\text { other group members }\end{array}$ & $\begin{array}{l}\text { Males will take more risks to } \\
\text { gain and maintain status. }\end{array}$ & Sexual selection \\
\hline Self-protection & $\begin{array}{l}\text { To protect oneself and } \\
\text { alliance members against } \\
\text { threats to survival or } \\
\text { reproduction }\end{array}$ & $\begin{array}{l}\text { Potential threats or costs will } \\
\text { lead to reciprocal exchange of } \\
\text { aggressive behavior, } \\
\text { particularly among non-kin. }\end{array}$ & Inclusive fitness \\
\hline Mate choice & $\begin{array}{l}\text { To obtain a partner or } \\
\text { partners who will enhance } \\
\text { one's own fitness }\end{array}$ & $\begin{array}{l}\text { Males will be, compared with } \\
\text { females, generally more } \\
\text { inclined toward an unrestricted } \\
\text { mating strategy (i.e., multiple } \\
\text { mates, shorter courtship before } \\
\text { sex). }\end{array}$ & $\begin{array}{l}\text { Differential parental } \\
\text { investment }\end{array}$ \\
\hline $\begin{array}{l}\text { Relationship } \\
\text { maintenance }\end{array}$ & $\begin{array}{l}\text { To maintain a mating bond } \\
\text { with a desirable partner }\end{array}$ & $\begin{array}{l}\text { Males will be inclined to break a } \\
\text { bond if a partner is sexually } \\
\text { unfaithful or if there are } \\
\text { physically attractive } \\
\text { alternatives available. } \\
\text { Females will be inclined to break } \\
\text { a bond if a partner } \\
\text { compromises resources or if a } \\
\text { high-status alternative is } \\
\text { available. }\end{array}$ & $\begin{array}{l}\text { Differential parental } \\
\text { investment }\end{array}$ \\
\hline Parental care & $\begin{array}{l}\text { To promote the survival and } \\
\text { reproduction of individuals } \\
\text { carrying one's genes }\end{array}$ & $\begin{array}{l}\text { Familial provision of resources } \\
\text { and care will follow the order } \\
\text { (a) self }>\text { siblings; (b) own } \\
\text { offspring }>\text { stepchildren }\end{array}$ & Inclusive fitness \\
\hline
\end{tabular}




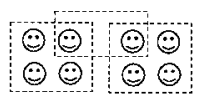

Coalition Formation

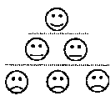

Status

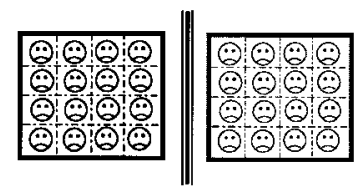

Self-Protection

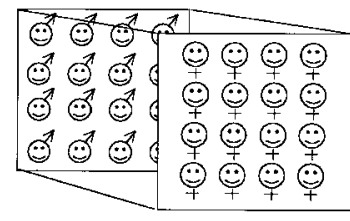

Mate Choice

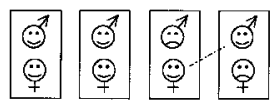

Relationship Maintenance

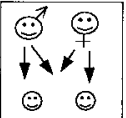

Parental Care

Figure 2. Network geometries associated with each social domain. Symbols indicate individuals involved in different forms of social interaction. As described more fully in the text, different decision rules used in different domains of interaction are presumed to result in different social geometries.

not be friends with one another but who are likely to meet under friendly circumstances). Loose overlap between groups is expected because reciprocal alliances between individuals in different families are likely not only to be tolerated by but also appreciated by other family members (if you help my family members, you have, from an inclusive fitness perspective, helped me). As we discuss below, decision rules following from an inclusive fitness principle lead to the expectation of a very different dynamic geometry for self-protection.

\section{Status}

For both sexes, adaptive advantages of gaining and maintaining status include access to material resources and extended social alliances. Around the world, "dominant" versus "submissive" is one of the two primary dimensions with which people categorize members of their groups (White, 1980; Wiggins \& Broughton, 1985). (The other primary dimension is "agreeable" vs. "disagreeable," intimately linked to friendship and coalition formation.)

For males, status has an important additional benefit from an evolutionary perspective, because females are more likely to use male status as a cue for mate selection (Kenrick, Neuberg, Zierk, \& Krones, 1994; Li, Bailey, Kenrick, \& Linsenmeier, 2002;
Sadalla, Kenrick, \& Vershure, 1987; Townsend, 1992). Consequently, males are, compared with females, more likely to pay attention to possible loss of status relative to neighbors (Daly \& Wilson, 1988; Gutierres, Kenrick, \& Partch, 1999).

As depicted in Figure 2, the dynamics of status competition often result in hierarchical arrangements of the individuals in a network. That is, the eventual self-organization resulting from iterated competitions over status will result in layers, with progressively fewer individuals in higher layers. Consistent with our earlier reasoning, there is evidence that male relationships with other group members tend to be relatively more hierarchical, whereas females tend to be relatively more egalitarian (McWilliams \& Howard, 1993).

\section{Self-Protection}

Ancestral humans frequently confronted threats from members of other groups (Baer \& McEachron, 1982; Diamond, 1997). Because of the inherent scarcity of high status positions and frequent scarcity of resources, there were also recurrent threats from in-group members (Daly \& Wilson, 1988). Decisions about self-protective behaviors, including violence, would have been based on information about another's in-group-out-group status, degree of kinship, past history of aggressiveness, and gender. Unrelated members of out-groups would have been more dangerous, because they did not share the individual's genetic selfinterest. Kin, on the other hand, would have been less dangerous, because imposing punitive costs on individuals who share one's genes exacts a cost on one's own inclusive fitness (Daly \& Wilson, 1988).

Between groups, self-protective decisions should lead to dynamics very different from those found in coalition formation. Rather than loosely overlapping networks, threats across groups should promote the formation of nonoverlapping mutually exclusive alliances, as depicted in Figure 2. Although intrinsic management problems make large groups less appealing for the usual day-today cooperative alliances (think of getting 50 different opinions about how the meal should be prepared or what the group should do for a recreational outing), there are greater advantages to large groups for self-protection-a factor that may have contributed to the emergence of human aggregations much larger than small family groups (Diamond, 1997).

Within groups, interesting dynamics emerge from the intrinsic trade-off between defensive aggressiveness and cooperative alliance formation. Living among non-kin, as many modern urban dwellers do, would result in the use of lower aggression thresholds, and hence neighborhoods should be more likely to stabilize into mutually maintaining regions of hostility. We return to these trade-offs below, because they form the basis of one of the simulation series we present.

\section{Mate Choice}

Given that differential reproduction is at the heart of natural selection, decisions about mating are of central adaptive significance. The goal of obtaining a partner to enhance one's fitness involves processing information regarding another's sex, attractiveness, health, relatedness, age, resources, and status (e.g., Cunningham, Druen, \& Barbee, 1997; Kenrick, Gabrielidis, Keefe, \& 
Cornelius, 1996; Kenrick \& Keefe, 1992; Sadalla et al., 1987; Shepher, 1971; Singh, 1993). Mating decisions will also involve informational inputs relevant to the number and attractiveness of other individuals in the mating pool (Guttentag \& Secord, 1983; Kenrick et al., 1994).

Table 1 focuses on one key sex difference that has been observed in mating behavior across a number of species (Geary, 2000). Males are, compared with females, generally more inclined toward obtaining multiple mates. Because of higher parental investment by female mammals, the costs of a poor mating decision will weigh more heavily for females than for males (Kenrick, Groth, Trost, \& Sadalla, 1993; Kenrick, Sadalla, Groth, \& Trost, 1990; Trivers, 1972). This is not to say that females will never engage in multiple matings or that males are not inclined toward monogamy, only that the sexes have different decision thresholds. Although females will be, compared with males, relatively more inclined toward restricted mating strategies, there are circumstances under which women will adopt unrestricted strategies (Buss \& Schmitt, 1993; Gangestad \& Simpson, 2000; Mikach \& Bailey, 1999).

There are a number of interesting features of mating dynamics, which we consider at later points in the article. Figure 2 focuses on one feature important to our later discussion. Individual mating decisions made by the members of one sex will be affected by the pool of locally available members of the opposite sex and vice versa. Because each sex must play out its mating strategies in the context of locally available members of the other sex, this leads to an interesting dynamic involving direct and indirect bidirectional influences. This sets up an interesting two-layer version of the sorts of dynamic social influence networks examined by Nowak and Latané and their colleagues (Latané \& L'Herrou, 1996; A. Nowak, Szamrej, \& Latané, 1990). Processes of social influence between neighbors in such networks lead to emergent phenomena such as local polarization combined with the emergence of minority clusters (Latané, Nowak, \& Liu, 1994). In a series of simulations we present below, we explore some interesting implications of sex differences in mating decision criteria within spatial networks in which the influence of same-sex neighbors on one another is indirectly mediated via influence on the members of the other sex.

\section{Relationship Maintenance}

Because human infants are helpless and develop slowly, the inputs of both parents are often essential to their survival (Geary, 1998; Hrdy, 1999). Although human mating arrangements vary from culture to culture, all involve long-term cooperative relationships in which both the male and female contribute to the offspring's welfare (Daly \& Wilson, 1983; Geary, 1998). Hence, a key adaptive problem for both sexes, involving issues beyond mate choice, is to maintain mating bonds with desirable partners (Buss, 1999; Hazan \& Diamond, 2000).

Not all relationships are equally desirable, and not all partners will be equally motivated to maintain a given relationship. Hence, decisions to maintain or terminate a relationship involve trade-offs, and these are intrinsically dynamic, involving inputs from both partners. Informational inputs relevant to relationship maintenance include the existence of offspring, availability of resources to both parents, presence and attractiveness of same-sex interlopers on the social horizon, and the sex ratio in the remainder of the mating pool (Dijkstra \& Buunk, 1998; Guttentag \& Secord, 1983; Kenrick $\&$ Trost, 1987). If a couple has offspring, for example, that raises the threshold for decisions to leave a relationship for an alternative (Essock-Vitale \& McGuire, 1989; Hoffman \& Manis, 1978; Rasmussen, 1981). Local availability of attractive alternatives, on the other hand, lowers the decision threshold (Guttentag \& Secord, 1983; Kenrick et al., 1994).

As noted in Table 1, decision rules for maintaining or terminating relationships are expected to be slightly different for males and females. This follows from considerations such as internal gestation and different types of resources contributed to offspring (females contribute bodily resources, males contribute indirect resources such as food and shelter). Because of internal gestation, only the female can be $100 \%$ certain that the offspring carry her genes. Males who stay in relationships with unfaithful partners face the danger of investing in offspring not their own. On the other hand, females confronted with reproductive competitors for their mate face the potential danger of loss of all or part of their partners' resource inputs to existing offspring (Buss, Larsen, Westen, \& Semmelroth, 1992). Females' commitment to their partners may be undermined by the local availability of other males with higher status or resource potential; males' commitment is more likely to be undermined by local availability of females manifesting cues associated with fertility and health (Guttentag \& Secord, 1983; Kenrick et al., 1994).

Although mating relationships are cooperative alliances of a sort, issues of parental investment inspire intense feelings of jealousy that bias toward a different interpersonal geometry. Indeed, although most human societies permit polygamous marriages, there is an inherent conflict of interest between individuals sharing the same partner. Hence, the most common arrangement, even in polygamous societies, is a pair bond (Daly \& Wilson, 1983). This is the pattern depicted in Figure 2. The dashed line between individuals outside official pairs reflects the possibility of extrapair mating behaviors, which can contribute importantly to the dynamics of relationship maintenance, as discussed above. Over time, the formation and dissolution of pair bonds has implications for the dynamics of mate choice. As some individuals are removed for long periods from the mating pool, and others are returned, this likely affects the mating decisions of others.

\section{Parental Care}

As noted earlier, parental care is critical to the survival of human offspring (Geary, 2000; Hrdy, 1999). In a number of species, including humans, older siblings also occasionally assist parents in providing care for the young (Alcock, 2001). Humans often occasionally provide parental care for grandchildren and nieces and nephews. However, nurturing for relatives, even one's own offspring, is not a constant but varies according to a number of factors (Daly, 1989; Hrdy, 1999). Decisions about care of any particular offspring, for example, may be affected by age of the offspring (which relates to reproductive value), presence of other offspring, other kin in the vicinity (who can lighten parenting demands), and care provided by the other parent.

Within the family, there will be competing decision rules regarding the optimal provision of nurturing resources, as indicated in Table 1. These follow directly from considerations of inclusive 
fitness (Daly, Salmon, \& Wilson, 1997). Parents share half their genes with their offspring. Full siblings also share roughly half their genes with one another. Although it may seem obvious to say that the individual shares all of his or her genes with himself, Trivers (1974) has shown that this leads to nonobvious implications for intrafamily conflict. The child and parent, for example, will differ in their preferences regarding allocation of resources to self versus sibling. A benefit from a parent to either of two healthy children has an equal effect on inclusive fitness from the parent's perspective. From the perspective of the individual child, however, a resource provided for a sibling is only half as beneficial to inclusive fitness as a resource provided to the self.

The one-way arrows between parent and child in Figure 2 are meant to suggest that the flow of resources between parent and child tends to go in one direction. This would follow from considerations of age-linked changes in both capacity and reproductive value. Early in life, children have few resources to offer and great need. Later in life, when they have accumulated resources, their parents' reproductive potential has declined. Hence, their inclusive fitness is then generally better served by investing in their own offspring. There are exceptions to this in humans and other animals. For example, in many bird species, mature individuals may assist their parents in raising the next generation when doing so is most likely to increase their own inclusive fitness. For example, bee-eaters help at the nest when both biological parents are still alive and when their own attempts at nesting have failed. They are less likely to help if one of the biological parents has been replaced by a stepparent, and when a pair re-nests near one of their parents, the nonrelated member of the pair does not help raise the other's siblings (Alcock, 2001; Emlen, Wrege, \& DeMong, 1995).

To summarize our discussion of the general framework, an evolutionary perspective, which focuses on adaptive problem domains, suggests particular decision rules that might contribute to the emergence of different dynamical patterns in different social domains. The list of decision rules in Table 1 is not offered as a complete one. However, the number of information-processing rules affecting individual behavior in social groups and the interactions between dynamics within each domain is likely to be finite-constrained by the priorities of successful reproduction on the one side and the intrinsically self-organizing properties of group dynamics on the other.

\section{Trade-Offs, Individual Differences, and the Emergence of Culture}

Interesting nonlinear dynamics often emerge from trade-offs between competing powerful motivations (Tesser \& Achee, 1994; Zeeman, 1976). From an evolutionary perspective, such trade-offs are an intrinsic part of adaptive decision making (Alcock, 1998a; Gangestad \& Simpson, 2000). Efforts expended to attain one of the fundamental goals listed in Table 1 may be incompatible with attaining another. For example, decisions about conflict with neighbors involve trade-offs between approaching benefits gained through cooperation versus avoiding dangers through self-protection.

Because each decision involves trade-offs, the decision criteria are not constant but reflect assessments of differing costs and benefits for particular individuals in particular situations. Indeed, each of the decision rules in Table 1 implicitly involves variation as a function of circumstances: They are all if-then statements rather than unconditional operating rules. Whether an individual decides to act cooperatively or self-defensively or to adopt a restricted or unrestricted mating strategy will vary within and across individuals as a function of recent experience and past history-vicinity to relatives, availability of mates, own stage of the reproductive cycle, and so on.

Individual differences are intrinsically involved in setting these trade-off points. For example, if-then rules used by males and females will differ in several domains, as noted. Other individual differences are expected on the basis of developmental history and random variation. As we attempt to show below, a dynamical evolutionary perspective may help clarify some longstanding confusion about interactions between individual differences and situational pressures.

Figure 2 depicts the structure of networks in more or less static terms. The benefits of thinking in dynamical terms become apparent however, in examining changes over time. Latané and colleagues have presented compelling demonstrations that, over time, individual differences can combine with normal social influence processes to explain the emergence of culture (Latané, 1996; Latané \& Bourgeois, 1996). Using simulations of social influence processes, Latané and Bourgeois (1996) demonstrated how the tendency for people to be more influenced by neighbors combines with initially random individual differences to lead, via selforganizing dynamic principles, to clustering and consolidation of subcultures. Latané's analysis was not concerned with the specific content or origin of individual differences. However, a consideration of the content of decision rules discussed above can combine with Latané's dynamical social influence perspective to yield some rich insights about processes of gene-culture coevolution.

\section{Testing Implications of the Dynamical Evolutionary Model}

The dynamical evolutionary perspective has implications for all the subdisciplines of psychology, and testing those implications will require a nomological network of findings using the full range of research methods. Survey data can be useful in generating hypotheses about the decision rules involved in hypothesized psychological mechanisms, and controlled experiments are useful for calibrating how those decision rules operate under varying conditions (e.g., Burnstein et al., 1994; Kenrick et al., 1990; Sadalla et al., 1987). Cross-cultural and developmental research is useful for establishing plausibility of hypothesized evolved mechanisms and their sensitivity to ecological variations (e.g., Daly \& Wilson, 1983; Kenrick \& Keefe, 1992). Besides the everyday tools of the psychological research trade, however, the dynamical perspective has also relied on recent advances in computer-assisted modeling (A. Nowak \& Vallacher, 1998). Like the perspective provided by cross-species comparisons, computer modeling can help limit the range of plausible hypotheses about human decision making. Computer simulations can extend human reasoning, allowing tests of assumptions about natural systems too complex for the human mind to normally process. As Latané (1996) put it, "Computer simulation can be used as a 'derivation machine,' a way of finding out what theories predict" (p. 18).

Like all methods, simulations have limitations as well as strengths. Simulations share a limitation of laboratory experimen- 
tation-that of limited ecological validity. If the variables manipulated in an experiment or programmed into a computer are invalid, the outcomes will not reflect complex processes in the real world. With regard to laboratory experimentation, however, Mook (1983) advanced some thought-provoking arguments "in defense of external invalidity" (p. 379). If one wishes to know what actually does occur in natural settings, descriptive methods such as naturalistic observation or archival investigation are often optimal. However, descriptive methods yield intrinsically noisy data, often poorly suited to isolating causal processes. Artificial laboratory experiments, on the other hand, are not useful in providing information about what actually occurs in natural settings but are quite informative about what could occur if certain conditions were met. Similarly, dynamic simulations may have a special role in scientific thinking. Like experiments, simulations provide an opportunity to observe particular processes in isolation from the natural sources of extraneous influence. Computer simulations are the ultimate example of this, bypassing the human analogues, and reducing the isolated processes to clean mathematical rules (Holland, 1998).

In this regard, Holland (1998) noted that computer simulations hold an interesting place between theory testing and empiricism. Models have always been central to scientific theorizing. They allow theorists to observe the workings of simplified systems without the constraints of the many sources of extraneous influence that operate in the greater complexity of the real-world system. Whereas traditional model building was partially limited by human cognitive capacities, computer simulations can test logical implications of complex interactive assumptions extending well beyond the $7 \pm 2$-bit ceiling on active memory.

Although simulations are necessarily simplified models of the real world, they may be most useful when they follow Cialdini's (1995) suggestion for laboratory experimenters - to cycle back and forth between empirical observations of complex natural phenomena and the simpler and more controllable, but artificial, world of the laboratory. In this light, consider the standard high-school version of the cycle of science, in which observations lead to theories, which lead to hypotheses, which lead to additional observations, and so on. In the traditional cycle, the process of theory building was done inside the head, including and excluding inferences based on logic. This process is intrinsically limited by the capacities of the human brain. Computer simulations allow an additional step between theory construction and empirical data collection- by allowing the computer to play out a set of assumptions too complex for normal logical limitations. In a sense, such simulations allow researchers to see a few feet further into the implications of their premises.

In simulating the interactions between people in a social group, one begins with initial values based on logical analysis, theory, or existing empirical data that might be relevant. Simulations can provide information about whether initial estimates are logically implausible (resulting in outcomes that are inconsistent with known conditions in natural systems), or they can suggest the range of values within which one's initial assumptions might hold. To know whether the results provided by such simulations are based on appropriate rules, however, a full-cycle approach is required, moving between the highly artificial but perfectly controlled simulation and the sloppier real world. Each of these steps

is essential-neither raw empiricism nor logical analysis without data is sufficient.

To illustrate some of the implications of thinking in dynamical evolutionary terms, we present several simulations exploring how patterns of social dynamics at the group level might emerge from individual differences in decision rules related to two sets of evolutionarily significant trade-offs-those involving cooperation versus self-protective aggression and those involving restricted versus unrestricted mating choice. The "raw inputs" into the simulations we present are computational rules consistent with existing data and theory based on living organisms. Results of those simulations are then compared with known empirical phenomena.

\section{Self-Organization of Aggressive and Peaceful Behaviors}

In the first series of simulations, we explored individual differences in thresholds for peaceful-cooperative versus hostilecompetitive behavior within localized spatial networks (analogous to the actual spatial arrangements within which people have traditionally lived in villages or neighborhoods). In the community depicted in Figure 3, individuals must decide whether to adopt a hostile or peaceful demeanor toward their neighbors. Let us begin with the assumption that it is normally disadvantageous to be in a minority within one's immediate locale. If one's neighbors are predominantly peaceful, hostile behaviors elicit unnecessary and potentially costly conflicts. If one's neighbors are predominantly hostile, pacifism opens one up to exploitation. Assume further that each individual responds directly to neighbors in adjoining dwellings, who respond to their own contiguous neighbors, and so on. The left half of Figure 3 depicts such a neighborhood on "Day 1." Individuals adopting a hostile strategy are depicted as dark circles, and those adopting a peaceful strategy are depicted as open circles.

For this simulation, individuals update on a daily basis and change their behavior if over $50 \%$ of immediate neighbors are

DAY 1

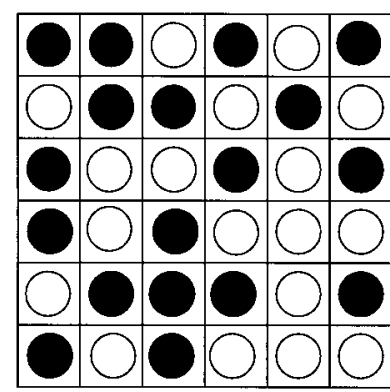

DAY 14

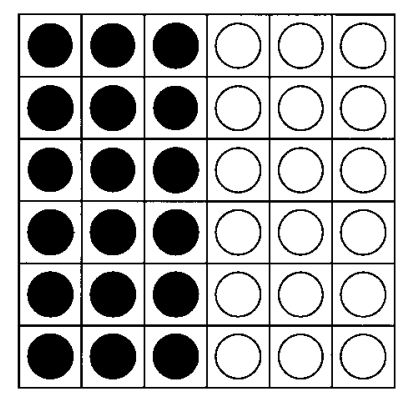

$$
\begin{aligned}
& O=\text { Hostile } \\
& =\text { Peaceful }
\end{aligned}
$$

Figure 3. Peaceful and aggressive behavior in a neighborhood on Day 1 (left) and Day 14 (right). Dark circles indicate individuals manifesting aggressiveness; white circles indicate individuals acting peacefully. Individuals use a simple majority rule to decide on a strategy for the next day-they will change if the majority of their neighbors are playing a strategy different from their own. The initial arrangement of behaviors in the neighborhood on the left stabilizes into two self-maintaining pockets after several days. 
playing the other strategy. Otherwise, each sticks to the current behavior. Relevant neighbors are all adjacent cells, including those on diagonals. Thus, the individual in the upper left-hand corner considered inputs from three neighbors-on the right, directly below, and below on the diagonal. Individuals in the center considered inputs from eight adjacent cells, and those on the edges from the five adjacent cells. ${ }^{1}$ If individuals average their neighbors' behaviors to recalibrate their own strategies daily, what will happen in 2 weeks? In the first iteration, the individual in the top row, fourth column, for example, began aggressively but will change on Day 2, because the majority of his neighbors are peaceful. However, his peaceful neighbor to the left (top row, third column) will change to an aggressive strategy to match the majority of his neighbors. Each individual's decision on a given day will thus have direct and bidirectional effects on immediate neighbors, and time-lagged effects on neighbors' neighbors. Conversely, every neighbors' decisions have direct or indirect influences on each individual.

Unaided intuition might lead to the expectation that such an initially random array might, via these repeated processes of multidirectional influence, continue as random, disordered, or chaotic fluctuations. But intuition can here be supplemented with the power of computer technology, allowing us to calculate the outcomes of many such complex dynamic networks at speeds well beyond those of the unaided human mind. Using a simple spreadsheet, one can rapidly calculate many iterations. In this case, the somewhat messy array depicted on the left converges on the much neater array shown on the right.

The outcome in Figure 3 depicts a process of self-organization ubiquitous in such systems (e.g., Latané, 1996; A. Nowak et al., 2000; Schelling, 1971). Our results are consistent with Latané's (1996) dynamic social impact theory, which suggests that individuals influencing one another within spatial arrays will demonstrate consolidation, clustering, and continuing diversity. There is nothing magical about such self-organizational processes. Initially random conglomerations transform into self-stabilizing patterns because, if each individual averages neighbors' inputs, local majorities automatically convert any deviant cells encompassed within them. Similar self-organized patterns emerge in simulated networks of neurons, genes, and many other systems in which information is exchanged between units connected in a web-like "neural network." Some systematic studies of actual human beings communicating in such networks have revealed similar convergence from initially random configurations toward locally selforganized pockets of opinion (Huguet, Latané, \& Bourgeois, 1998; Latané, 1996). For example, Latané and L’Herrou (1996) had subjects guess their group's majority opinion on several topics (e.g., preference for one of two professional basketball players or one of two magazines). Subjects were permitted to revise their estimates after checking with contiguous neighbors, connected in arrangements analogous to that in Figure 2. Rather than achieving consensus, subjects often organized into minority pockets-each highly confident they were correct, because they were surrounded by a clear local majority.

Those familiar with work on complex dynamical systems will recognize these neighborhoods as examples of cellular automata (e.g., A. Nowak \& Vallacher, 1998; Wolfram, 1986). As noted earlier, a cellular automaton is a system in which a number of simple elements are arranged in a spatial pattern, and the state of any element at a given point in time is determined by the state of its neighbors at the preceding point in time. A distinctive feature of such systems is that interactions between simple elements often lead to the emergence of global patterns that were not programmed into the elements (A. Nowak et al., 2000). The development of stable minority pockets (as in Figure 3), for example, was not specifically programmed into the system but emerged from the interaction of individuals using the simple rule of averaging neighbors' inputs.

\section{Genotypic Traits and Phenotypic Behaviors in Dynamic Networks}

In the first series of simulations, we conceptualized traits as underlying genotypic decision rules that were universally shared by all individuals. Tooby and Cosmides (1990) hypothesized that phenotypic variation in behavior could result from the operation of universal monomorphic traits, if those traits are conceptualized as contingent decision rules calibrated to environmental variation. The conceptualization of a trait as a flexible decision rule is important for evolutionary theorists. Traits in this sense are central to the process of natural selection (which involves random variation and selective retention of characteristics leading to recurrently adaptive behaviors). A consideration of dynamically interacting networks helps clarify why behaviors can change even if underlying traits do not. Note that the individuals represented by the cells in Figure 3 never actually changed their underlying decision rules, although many of them did change their overt behaviors to match those of their neighbors, thereby reaching the eventual equilibrium depicted on the right side of the figure. Depending on context, the same underlying decision rules manifested themselves as either aggressive or peaceful overt behaviors. ${ }^{2}$ This illustrates a key point for evolutionary psychologists - to say that an individual has a trait is not to say that his or her overt behavior is insensitive to the environment (Buss \& Kenrick, 1998; Kenrick, 1995). Rather, the behavioral manifestation of a given genotype depends critically on inputs from, and reactions to, the environment.

\footnotetext{
${ }^{1}$ It is possible to have the individuals at the edges "fold over" and take inputs from the contralateral cells (e.g., Latané \& L'Herrou, 1996). We wished to maintain the actual spatial arrangements likely to be found in a small village or neighborhood (which do have edges). It is also possible to have individuals take inputs from more distal neighbors, often weighted to reflect greater influence with more proximity. In the models we test here, direct inputs come only from immediately contiguous neighbors, and influences of more distal neighbors are indirect and time lagged (to the extent that the behaviors of distal cells eventually influence immediate neighbors). In any event, spatial self-organization emerges in systems such as these regardless of these variations (Latané, 1996).

${ }^{2}$ The decision rules considered in these simulations would act the same whether they were conceptualized as inborn or learned. Simulations have often been concerned with experience and learning, in which case the decision rules would themselves update their criteria on the basis of experience (Holland, 1998). Although trait theorists and evolutionary theorists generally assume that traits in adult humans are a product of an interaction between genotype and experience, it is interesting to see that stable phenotypic variations can be maintained by local dynamics even if one were to assume inflexibility in underlying decision rules and no individual differences (i.e., with all people having a universal and monomorphic preference with regard to a given problem).
} 
The same point is made by psychologists who study personality traits: Extraverts are generally more likely to be friendly than introverts, but they are not friendly in all situations, nor are introverts unreservedly reserved (Kenrick \& Funder, 1988). A psychological trait is perhaps best represented not as an enduring "feature" (like a physical trait), but as a decision-making rule that produces different outcomes depending on interactions with the social context. Within the dynamical networks that make up real social environments, the distinction between underlying trait and overt behavior is essential. The physical trait of eye color may not manifest itself differently from one situation to the next, but the psychological trait of irritability does. Indeed, most behavioral traits are intrinsically defined by the way in which they link overt behavior to ongoing dynamics in the physical or social environment.

To say that underlying traits unfold into different behaviors within dynamic social networks, however, is not to say that the social environment is all. When we model the effects of different individual predispositions within the sort of matrix portrayed in Figure 3, results indicate that one or two individuals with an unusually hostile predisposition (in the sense of a differentially low threshold for aggression) can sometimes change a whole neighborhood.

Figure 4 depicts the outcome of an identical initial "Time 1" state in four neighborhoods. In Outcome A, depicted at the top right, all individuals have the same underlying predispositionthey use the majority rule to decide whether to act aggressively or peacefully. Under these circumstances, the initial embers of aggressiveness flicker out, and the community eventually reaches a totally peaceful equilibrium. In Outcome B, one solitary individual (in the second column, second row from the bottom, as marked) is set to have a "short fuse"- his threshold for hostility is such that he will act aggressively if any one of his neighbors does so. Although this individual is one small voice in the neighborhood, it becomes a loud one, and instead of settling into peacefulness, the network 2 weeks later includes a reasonably large self-maintaining pocket of hostility. Outcome C shows that another "touchy" individual in a different spatial location has, alone, no effect on the eventual outcome. However, the combined effect of those two individuals at the system level is profound (Figure 4D). Despite the fact that these two low-threshold individuals constitute less than $6 \%$ of the population, the systemwide outcome in Figure 4D is completely opposite that depicted in Figure 4A, and the neighborhood settles into a uniformly hostile equilibrium. Note that at this point, the two short-fused individuals could move out and be replaced by two residents with normal hostility thresholds, but the hostile dynamic would continue.

Individual differences thus have profound implications for network dynamics, consistent with a point made by researchers studying person-environment interactions: Traits inside individuals do not respond passively to environments but may dramatically alter the environments within which their bearers interact (Endler \& Magnusson, 1976; Hettema \& Kenrick, 1992; Snyder \& Ickes, 1985). These results parallel Rausch's (1977) classic interactionist observation that an aggressive child unleashed on a peaceful playground could sometimes turn it into a battle zone.

A complexity theorist focusing on general processes of emergence might note that despite individual differences, these neighborhoods always end up being drawn into some stable attractor
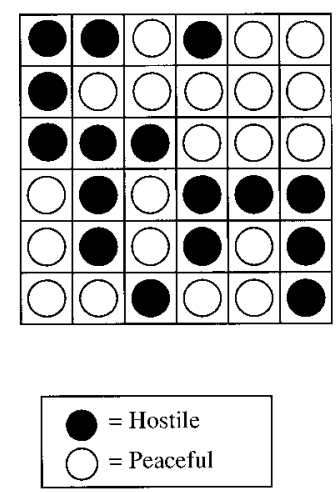
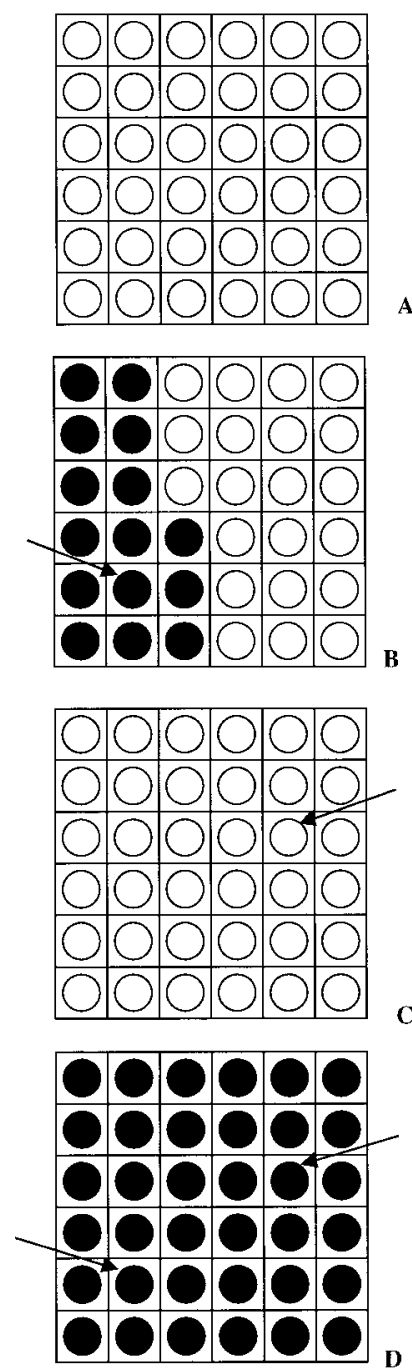

Figure 4. Aggression in four neighborhoods that began with the identical initial arrangement of overt behaviors (shown at the top left). Outcome A shows the equilibrium if all individuals use the normal majority rule. Outcome B shows equilibrium if one individual (marked with an arrow) has a low threshold (will act aggressively if any neighbors acted aggressively on the prior day). Outcome $\mathrm{C}$ shows equilibrium with another short-fused individual (marked with an arrow) in a different location of the same initial arrangement. Outcome D shows equilibrium with both shortfused individuals (marked with arrows) in the same neighborhood.

state. However, to those concerned with the survival and successful replication of particular traits and the organisms that possess those traits, the particulars of the eventual dynamic are everything. If the local network is frequently drawn into all-out warfare in response to a few individuals with a given predisposition, that has critical implications for which traits (or behavioral probability rules) will be selected in the population at large. Natural selection, in the sense of selective retention of particular traits in particular ecosystems, works within the general constraints of complex dynamical systems, but to understand any particular system in nature, the specific contents of individual traits and of group-level outcomes are both essentially important. 


\section{Initial Conditions Are Critical (Sometimes)}

There is another "interactionist" point that can be nicely illustrated in these dynamical networks. The importance of individual differences depends on the relative "strength" of the environment and vice versa (Price \& Bouffard, 1974; Schutte, Kenrick, \& Sadalla, 1985; Snyder \& Ickes, 1985). In the arrays pictured in Figures 3 and 4, initial behaviors were fairly evenly split between aggressive and peaceful. In the range of values around a 50/50 split, slight variations in the spatial location of individuals can have profound effects. In dynamic terms, the system manifests multistability within that range (i.e., the system settles on more than one state, given the same initial percentage of aggressive behavior but different initial spatial arrangements).

As noted earlier, dynamical systems theorists note that small changes can sometimes result in radically different outcomes in complex systems (Lewin, 1993; Waldrop, 1992). Tiny features of a system at Time 1 can radically change outcomes at a systemwide level (as in the fabled butterfly who flaps its wings over Brazil and sets off a cascade of air pressure changes that ultimately alter next week's weather in Chicago). The second short-fused individual had a profound impact in Figure 4D (when the other short-fused individual was present), but by himself, he had no impact on the eventual outcome (Figure 4C).

However, small variations do not always have important effects. When over $70 \%$ of initial behaviors are hostile, for example, the system always moves quickly into a totally aggressive dynamic and stays there. This is true even if none of the individuals in the neighborhood have a short fuse. At other initial values, individual differences in aggression thresholds may or may not lead the system to mixed outcomes, depending on the spatial arrangement of individuals in the matrix. As noted earlier, the values at which the system changes its general behavior are called bifurcation points. An exploration of the system's behavior has implications for understanding parallel natural systems - in this case, providing an idea of when individual differences in aggressiveness will matter at the systemic level and when they will not.

To begin exploring this system for bifurcation points, we ran a series of simulations varying two parameters-percent of initial behaviors that were aggressive and percent of individuals with low aggression thresholds. Results of 567 such simulations are shown in Figure 5. One third of those simulations were run with no low-threshold individuals, and initial percentages of aggressive behavior ranging from $0 \%$ through $100 \%$ (top panel). This was repeated using the same set of arrays, randomly adding nine low-threshold individuals for another 189 runs (middle panel) and likewise for 18 low-threshold individuals (bottom panel). We also used the same initial arrangements for intermediate values of 3 , 6,12 , and 15, not shown here. For each value, the same set of arrays was used, but three additional individuals within each array were randomly assigned to have a low threshold.

In the case when no individuals are set to a low threshold for aggression, the spatial arrangement of particular aggressive and peaceful behaviors makes no difference when the initial percentage of aggressive individuals is below 40 (in which case the system always settles into peacefulness), or above 70 (in which case the systemwide outcome is always total hostility). Note that dots on the graph at these extreme values represent multiple runs converging on the same $(0 \%$ or $100 \%)$ outcome. In the range around $50 \%$ initially aggressive, however, the system manifests multistability and can settle into either total peacefulness, total hostility, or some spatially organized combination of the two (as was seen in Figure 4).

When the number of short-fuse individuals is in the range of six to nine, the system is maximally unstable, and outcomes at any given initial value can vary widely depending on the vagaries of individual placement (as in the middle panel). As the number of short-fuse individuals goes above 12 , however, the system is again strongly drawn toward a single attractor state-total aggressiveness is the predominant outcome, even in most runs with low initial proportions of aggressiveness (as in the bottom panel of Figure 5).

In the technical terms used by dynamical systems theorists, as the number of low threshold individuals increases or as the percentage of initially aggressive behaviors within the neighborhood increases, the system tends to switch from a multimodal state (in which outcomes may be either all passive, mixed, or all aggressive) toward a unimodal state (in which the system always stabilizes with the same outcome). Using the dynamical terminology discussed earlier, we may say that variations in either control parameter in this system (initial behavioral ratio or initial number of low-threshold individuals) led to phase transitions (or qualitative changes in system outcome).

This first set of simulations highlights two other interactionist assumptions - that individual differences will matter more in some situations than others and, conversely, that situations will matter more for some individuals than for others (Endler \& Magnusson, 1976; Kenrick \& Dantchik, 1983; Snyder \& Ickes, 1985). Dynamic simulations allow more precise quantitative statement of the circumstances under which these person-situation interactions will and will not occur. Likewise, those who adopt a traditional evolutionary approach have understood that the overt manifestation of a phenotypic characteristic will be adaptively keyed to the environment. However, this understanding has generally been expressed in qualitative terms and has not been accompanied by explicit consideration of how group-level self-organizational processes unfold among individuals in spatially connected social webs.

\section{Sex Differences and the Dynamics of Mating}

Self-organization within complex dynamical networks offers an interesting way to frame another key issue for evolutionary psychologists- how males and females influence one another's mating options. In line with theory and data on differential parental investment, we hypothesized that the two sexes have different probability rules for decisions about sexual relationships, with males somewhat more inclined than females to take advantage of opportunities for "unrestricted" mating. Because each sex must play out its mating strategies in the context of locally available members of the other sex, however, this leads to an interesting dynamic involving direct and indirect bidirectional influences. As noted earlier, this can be conceptualized as a two-layer variation of the dynamic social influence networks examined earlier.

Figure 6 depicts a neighborhood in which each individual chooses whether to enact a restricted or unrestricted mating strategy. In our first simple model, based on the hypothesized social geometry in Figure 2, the members of one sex base their overt 

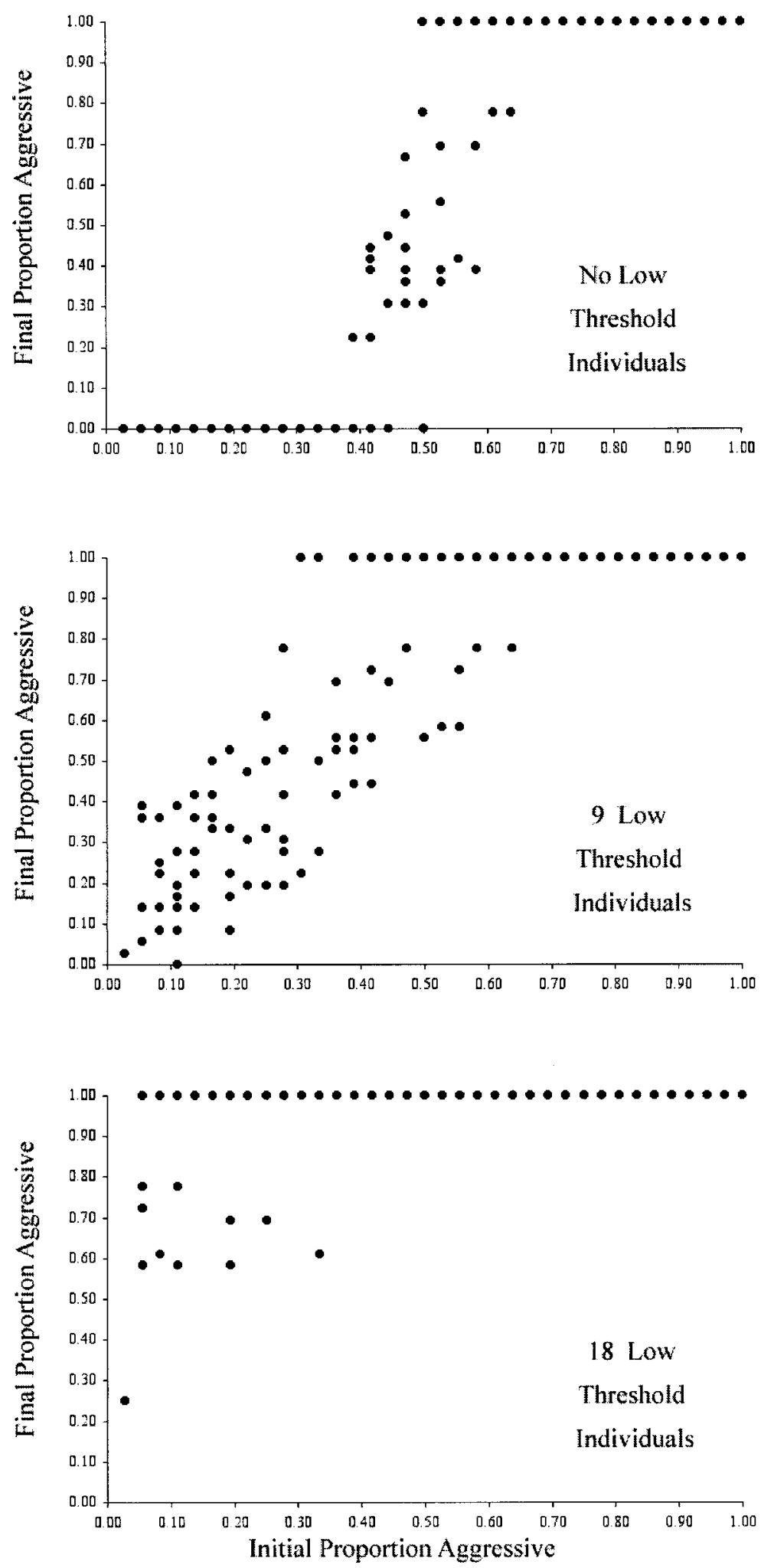

Figure 5. Outcomes of 567 simulations in which the numbers of low-threshold individuals and the numbers of neighbors who initially acted aggressively were systematically varied. 


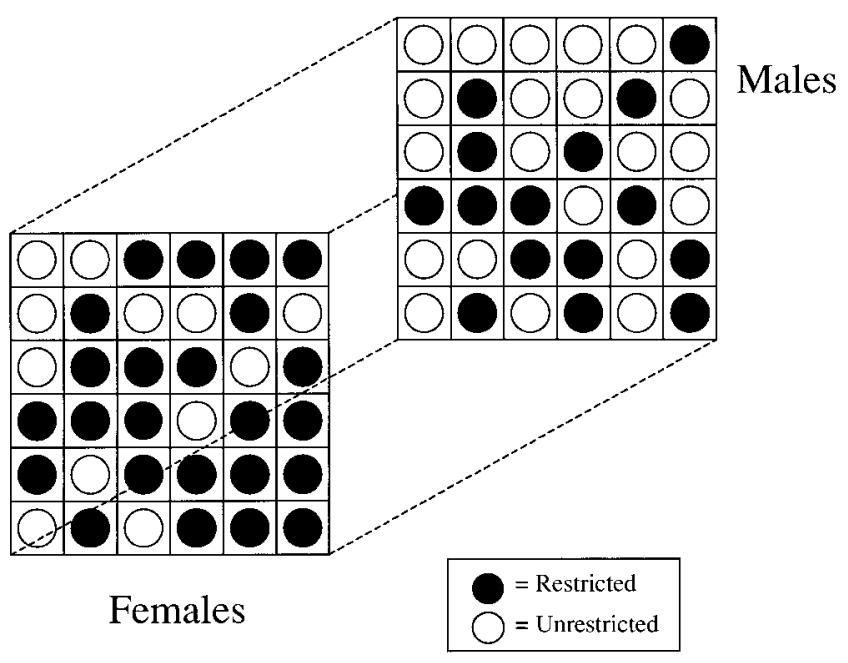

Figure 6. Mating behaviors manifested in a neighborhood-Time 1. Individuals observe the behaviors of the opposite-sex others in their immediate vicinity (contiguous cells) and decide whether to switch their behaviors or not, using the change rules shown in Table 2 .

mating behaviors on those of the contiguous members of the opposite sex. That is, the female in Row 2, Column 2 is affected by the males from Row 1, Column 1 through Row 3, Column 3, whereas the male in Row 3, Column 3 is affected by the females from Row 2, Column 2 through Row 4, Column 4, and so on.

Although evolutionary theorists have agreed about the general principles of sex differences in sexual selection and parental investment, there are a number of alternative hypotheses about how these differences apply to humans (e.g., Buss \& Schmitt, 1993; Gangestad \& Simpson, 1990, 2000; Graziano, Jensen-Campbell, Todd, \& Finch, 1997; Hazan \& Diamond, 2000; Hrdy, 1999; Kenrick et al., 1990; Kenrick, Groth, Trost, \& Sadalla, 1993; L. C. Miller \& Fishkin, 1997). For example, L. C. Miller and Fishkin (1997) argued that both sexes are primarily inclined toward monogamy, whereas Hrdy (1999) has advanced arguments that primate females in general, and human females in particular, are more promiscuous than is generally thought. Others have argued that human males and females have variable strategies keyed to differences in their own likely levels of parental investment and those of the opposite sex (Gangestad \& Simpson, 2000; Kenrick et al., 1990). In the simulations we present below, we explore implications of differing assumptions about sex differences and similarities in decision rules and how these play out at the community level. As we demonstrate, large effects at the group level can result from relatively smaller sex differences that get amplified by dynamic processes.

To provide an initial estimate of the change rules for males and females, we surveyed 53 undergraduate students (40 women, 13 men). Following Simpson and Gangestad (1991), those students read a description of a restricted strategy (person who requires love before engaging in sexual relations, does not desire multiple partners, etc.) versus an unrestricted strategy (willing to have sexual relations outside a serious loving relationship, would be comfortable having ongoing sexual relations with more than one person at a time, etc.). Students were asked to consider the women and men they know and to estimate what percentages they would guess to be restricted and unrestricted. They were also asked to estimate the percentage of opposite-sex individuals adopting a given strategy that would be required before a member of their sex would switch from their current strategy. On the basis of the student estimates, 15 of the 36 men (42\%) and 24 of the 36 women (67\%) were set to start out behaving in a restricted manner. Asking actual students provided a reasonable starting point for these simulations, but one need not place great faith in this method of estimation. Below, we explore what happens when these parameters are varied.

As indicated in Table 2, students estimated that both restricted and unrestricted members of their sex would be inclined to stick with their initial strategy unless confronted with something more than a simple majority among opposite-sex associates. As Table 2 further shows, they estimated that the size of that majority would differ depending on sex and initial strategy. Women judged a $62 \%$ majority of restricted males in a female's vicinity as sufficient to move her from an unrestricted to a restricted strategy, whereas restricted females were not expected to change unless $78 \%$ of local males were unrestricted. Male student judges also expected males to stick with their current strategies, but to be relatively more willing to shift to an unrestricted strategy.

We used these rough data merely to provide reasonable initial anchor points for our simulations. As we discuss below, the beauty of such simulations is that they can be modified to take account of alternative sources of data to ask "what if" the traits of the individuals involved or the local distribution of strategists were to change in various ways.

We ran 100 simulations with random placement of initial behaviors, restraining initial percentages of the two strategies and the change rules within each sex in keeping with the estimates described above. For example, a female who began behaving in an unrestricted manner would check the behaviors of contiguous males and change to restricted if $62 \%$ or more of them were restricted. Using these initial estimates, most neighborhoods stabilized with more restricted behaviors than they had at the start (averaging $82 \%$ of males and $86 \%$ of females, up from the $42 \%$ and $67 \%$ seed values). In $22 \%$ of cases, all members of both sexes ended up restricted, and in the remaining $78 \%$ of cases, the most common pattern was a small pocket of unrestricted males congregated around a slightly smaller pocket of unrestricted females. Figure 7 depicts one illustrative case using the normal rules with the initial spatial array from Figure 6 .

In no case did a whole community end up unrestricted when normal beginning rules were used. Those results are consistent with real-world data, such as findings that the majority of the adult population has only a small number of sexual partners, and most

Table 2

Decision Rules by Males and Females, as Estimated by Undergraduate Students of the Same Sex

\begin{tabular}{lcc}
\hline & \multicolumn{2}{c}{ of opposite sex needed to change from } \\
\cline { 2 - 3 } Sex & $\begin{array}{c}\text { Unrestricted to } \\
\text { restricted }\end{array}$ & $\begin{array}{r}\text { Restricted to } \\
\text { unrestricted }\end{array}$ \\
\hline Female & 62 & 78 \\
Male & 72 & 52 \\
\hline
\end{tabular}




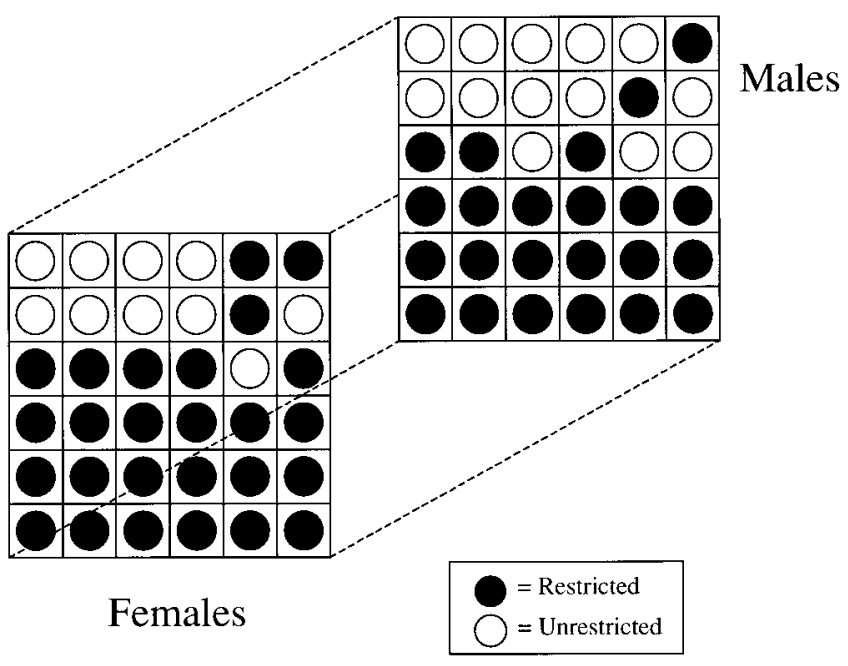

Figure 7. Equilibrium for the initial neighborhood in Figure 6, when normal rules are used.

end up spending their adult lives in pair-bonded relationships (e.g., Brehm, 1992; Michael, Gagnon, Laumann, \& Kolata, 1994). Results of one survey, for example, indicated that only $23 \%$ of men and $12 \%$ of women have had more than one sex partner during the past 12 months, and among married individuals, only 5\% have been unfaithful during the past 12 months (Michael et al., 1994). At the same time, the findings of minority conglomerations of unrestricted individuals in the simulated communities certainly have their parallels in the real world as well. Rather than attempting to actually spatially represent Amsterdam versus Tulsa, Oklahoma, however, these simulations allow us to ask questions about what would happen if the males or females in a given local network were to vary in their underlying predispositions. Another way to put this is to ask what would happen if the local norms were different for one of the sexes.

By chance alone, some locales will have relatively high proportions of unrestricted women or of restricted men. Other situational factors, such as sex ratios, can also move either sex toward a relatively more or less unrestricted mating strategy (Guttentag \& Secord, 1983). How would outcomes at the community level change in localities where females used relatively more unrestricted change rules akin to males or vice versa?

We re-ran the above simulation using the same initial seed values depicted in Figure 6 but programming females to change according to male rules (while males used their same rules). We also ran the simulations with males programmed to adopt female change rules, while females remained the same. Results based on the initial configuration depicted in Figure 6, when both sexes used male change rules, are depicted in the top panel of Figure 8. Results for the identical beginning array when both sexes used female rules are depicted in the bottom panel.

We ran the simulations with 100 different (random) initial placements, repeated three times (for each set of rules). Table 3 summarizes the results. When females were programmed to change according to male rules, the neighborhoods converged on unanimous unrestrictedness $78 \%$ of the time, with the remaining $22 \%$ of cases moving to mixed matrices, including a small minor- ity of restricted individuals (as in Figure 8, top panel). When males played by female change rules (with a stronger preference to change toward restrictedness), on the other hand, $97 \%$ of the networks converged on unanimous restrictedness. The disjunctiveness of these outcomes is interesting, considering not only that the initial ratios were identical in each case but also that the average differences in change rules were not radically different for men and women to begin with (as shown in Table 2). Without the benefit of a dynamical network, one might have estimated the outcomes simply by using a linear averaging process. If we had used a weighted average based on each individual's initial behaviors and his or her commitment to that particular strategy, results would have been much less extreme (closer to the $50 / 50$ or $60 / 40$ range, depending on which sex's decision rules were used). However, the actual outcomes (as shown in Table 3) were much more polarized. This disjunctiveness demonstrates another feature of dynamical systems mentioned earlier-outcomes do not follow from simple assumptions of linear combination.

Returning to our earlier discussion of underlying traits versus overt behavioral manifestations, note that males acted differently

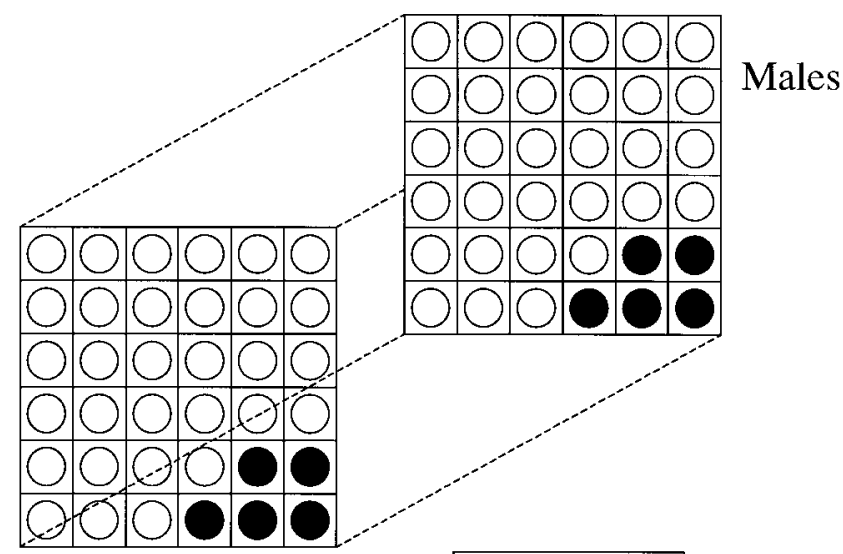

Females
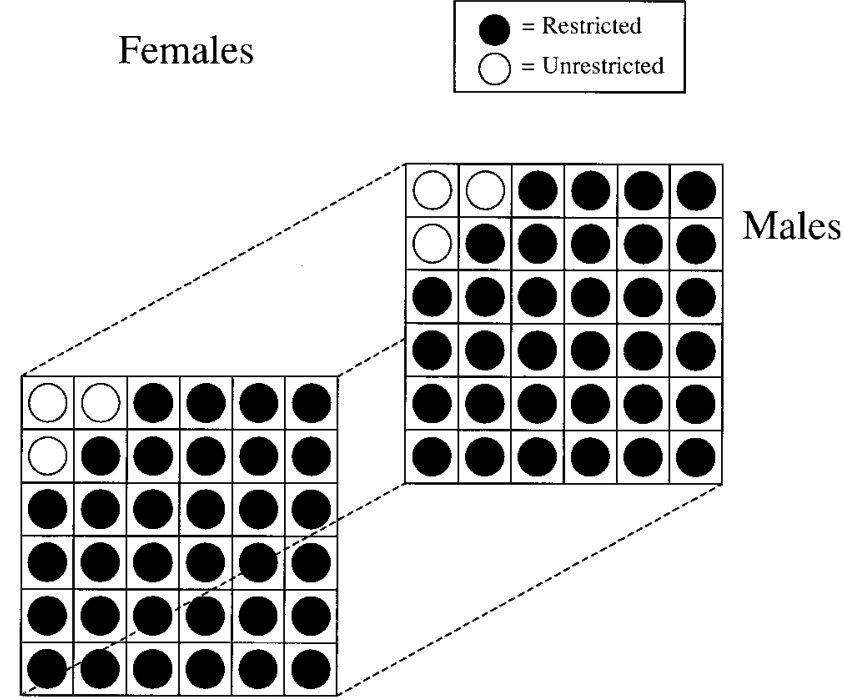

Females

Figure 8. Top panel: Equilibrium for initial neighborhood in Figure 6 if both sexes used male rules. Bottom panel: Equilibrium for same initial neighborhood if both sexes used female rules. 
Table 3

Percentages Playing Different Strategies on Final Iterations, as a Function of Differing Sets of Initial Rules

\begin{tabular}{lccc}
\hline & \multicolumn{3}{c}{ Final outcomes } \\
\cline { 2 - 4 } Change rules & All restricted & All unrestricted & Mixed \\
\hline Normal & 23 & 0 & 77 \\
All male & 0 & 78 & 22 \\
All female & 97 & 0 & 3 \\
\hline
\end{tabular}

Note. In all cases, original numbers of restricted and unrestricted behaviors by males and females were the same as in Figure 6, but the initial locations of individuals were randomly varied. For each random placement, a simulation was run using each of the three sets of rules.

when interacting with females playing by male rules, even though the males' underlying dispositions did not change from the normal rules. Note also that even after behaviors have stabilized into an apparent equilibrium, individuals are still checking and rechecking their neighbors, ever ready to alter their overt behaviors if ecological circumstances in their social networks change. Again, these simulations demonstrate how different local ecologies may induce a person to act very differently, even though his or her underlying trait, in the sense of his or her threshold for change, does not vary.

Consider again what happens when females play according to male rules. In this instance, nothing at all changes in the traits of the males, but now $78 \%$ of the groups end up completely unrestricted, and the majority of all mixed outcomes are also unrestricted. For a possible real-world parallel, consider surveys revealing vastly more sexual partners for homosexual than for heterosexual males (Bell \& Weinberg, 1978; Michael et al., 1994; Symons, 1979). Other evidence indicates that homosexual and heterosexual males are, in most ways aside from the sex of partners they desire, very similar in mating preferences (e.g., Bailey, Gaulin, Agyei, \& Gladue, 1994; Kenrick, Keefe, Bryan, Barr, \& Brown, 1995). These simulations support speculations that the very different numbers of sexual partners may follow from the simple operation of emergent dynamics, without assuming any differences in sex drive between homosexuals and heterosexuals. Such emergent dynamics may be most pronounced among homosexual males but should apply to some local populations of heterosexuals as well (Gangestad \& Simpson, 2000). Given that unrestricted and restricted males and females are necessarily spatially distributed (in random and nonrandom ways), there are likely to be local communities within which the emergent picture will be as disparate as the outcomes in Figure 8. Once unrestricted behavior becomes the local norm, for example, the majority dynamic will draw in even individuals whose inherent preferences lean toward restrictedness.

\section{Where Does the Buck Stop (and Where Does It Start)?}

What is the "real" stable state at which a population of restricted and unrestricted individuals will stabilize? On the basis of theory and data, we estimated that $42 \%$ of males and $67 \%$ of females would begin as restricted, yet the neighborhoods stabilized with $82 \%$ of males and $86 \%$ of females behaving in a restricted manner. Does this suggest that, over time and repeated attempts to enact their preferred mating strategy, most college students will end up restricted? And, if so, why is it that the majority of those males are not already restricted? There are several possible answers to this question. One is that young students are indeed in the early stages of a dynamic that will move more and more toward restrictedness. Evidence for this comes from the population statistics suggesting that although the majority of individuals in their late teens are still single, the majority of adults are married (U.S. Census Bureau, 2000). Indeed, the whole population would be expected to move toward restrictedness to the extent that individuals are randomly introduced to new networks over time. If we were to randomly reshuffle individuals after our neighborhoods had reached stability, for example, the new seed values would involve progressively fewer individuals manifesting unrestricted behaviors, and on each iteration, these individuals would be more likely to end up in majority pockets of restrictedness and thus switch over themselves.

Individuals at the beginning of their reproductive life spans may attempt to enact strategies that are not only sex differentiated but also somewhat randomly spatially dispersed. Although the majority end up in restricted mating arrangements, some percentage of individuals in the actual mating pool does remain unmarried for decades and even for lifetimes, and many continue to live a fairly unrestricted lifestyle. This may occur because potential mates are not randomly spatially reshuffled. Indeed, an individual may voluntarily remain in one place, or relocate, depending on whether or not the present social environment includes potential mates receptive to his or her current mating strategy. The potential for conditional migration adds a further complication to mating dynamics, but it is an interesting complication, and one that it is possible to model.

\section{Further Complexities: Migration and Sex Ratios}

The simulated neighborhoods we have discussed so far have had the constraint that interactions are limited to immediate neighbors. Such spatial constraints might well have applied and indeed might still apply in many traditional societies. Individuals living in remote rural areas are often limited to searching among their neighbors for potential mates, and indeed, even people in urban areas during this century have chosen mates who live in close proximity (e.g., Bossard, 1932; Moghaddam, Taylor, \& Wright, 1993). Mobility is common in modern society, however, and was likely an occasional option in many traditional societies (Cavalli-Sforza \& Cavalli-Sforza, 1995; Diamond, 1997). In the final set of simulations, we included the option for each individual to migrate in search of a social environment suited to his or her current strategy.

We also added another complicating factor to those simulations. Our model for the first set of mating simulations had only empowered individuals with the ability to consider behaviors of opposite-sex neighbors. In reality, what same-sex competitors are doing should matter as well. For example, if there were 10 restricted females and 5 unrestricted females around, a male might find it more beneficial to play a restricted strategy, all else being equal. However, if there were, at the same time, 40 restricted males but only 4 unrestricted males in the vicinity, the same male would face less competition per available mate and would have greater chances of success by pursuing an unrestricted strategy. Accordingly, we examined models in which individuals had the ability to consider relative sex ratios of local individuals playing each strat- 
egy (for a discussion on the effects of sex ratios on restrictedness, see Guttentag \& Secord, 1983).

Thus, the final set of simulations explores what happens when individuals consider the local sex ratios and are permitted to change location in search of a better sex ratio for their current strategy. In the aggression simulations, each cell could be conceived as representing a separate individual (perhaps located in a separate hut). In the mating simulations, each location is better conceived as a small village or apartment complex.

For these mobility simulations, local networks of males and females began with initial ratios used earlier (67\% of females and $42 \%$ of males began by adopting a restricted strategy). Further, the change rules from the earlier simulations were used to calculate two additional rules: one for when to move from the present location and one for when to change one's behavior. Females were again set to change more easily from unrestricted to restricted than were males. Before deciding in each trial whether to change their behaviors, however, individuals would first assess the best location for their current behavior. That is, each individual would first calculate the sex ratio of those playing the same current strategy in each neighboring cell. If any of the neighboring cells offered a better sex ratio for the current strategy, the individual would move to the neighboring cell offering the most favorable ratio for his or her current strategy (with the limitation that no more than 10 individuals occupy the same location). If no neighboring cell offered a better ratio for the current strategy, the individual would stay put for that trial. ${ }^{3}$ Following the decision to remain or move, each individual decided whether to change strategy on the basis of a comparison of the sex ratio for the current strategy versus the other strategy in the new location. Thus, an individual might move and still change, if all local options for his or her strategy were relatively unfavorable. ${ }^{4}$

Figure 9 provides an example, depicting the initial locations of individuals of each sex playing each strategy on the left. The distribution is depicted as a topographical map, with frequency of each strategy depicted separately. The initial distribution was random, with the limitation that the overall percentage of restricted females was $67 \%$, and the overall percentage of restricted males was $42 \%$. The right side of the figure shows what happened after 17 rounds, at which point the community had reached an equilibrium point, and all individuals had stopped moving or changing. Note that the initial distribution of restricted and unrestricted males and females (left) indicated no correlation between the positions of males and females playing the same strategy. At the end, however, a number of individuals had migrated so that, for example, the congregations of unrestricted females (lower right) were mirrored by a slightly higher congregation of unrestricted males. Likewise, restricted males and females had moved to congregate together.

Figure 10 plots the results from the matrix in Figure 9 temporally rather than spatially. Over time, the distribution of restricted behaviors increased slightly in males, whereas unrestricted behaviors decreased slightly. On average (over 100 trials), the initial distribution of males shifted from $42 \%$ restricted to $51 \%$, with females shifting from $67 \%$ restricted to $72 \%$. These results thus resembled those of the series run earlier without the mobility option except that the addition of mobility reduced the likelihood of individuals changing their behaviors. They were instead likely to migrate to a location where their current strategy would be a

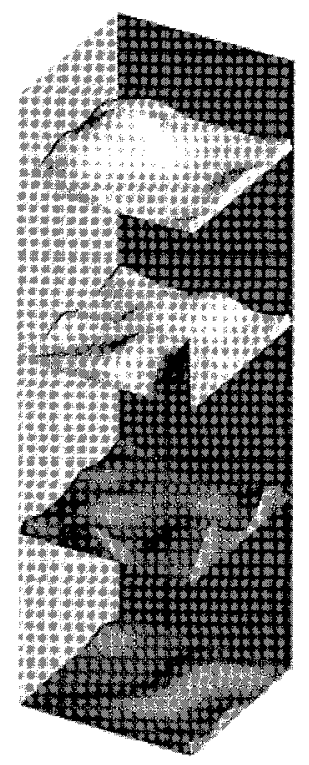

Initial Distribution

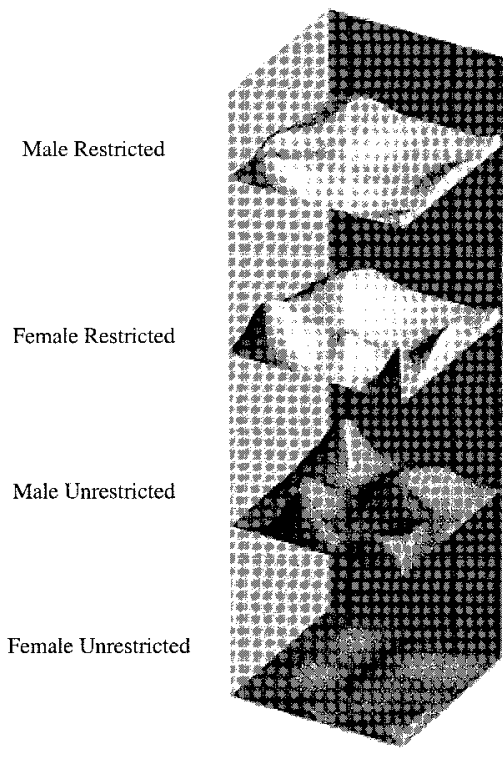

Distribution at Equilibrium
Figure 9. Left: Initial (random) spatial arrangement of individuals in one matrix, depicted topographically. Right: Location of restricted and unrestricted individuals at equilibrium. Note the higher spatial correspondence between males and females playing the same strategy at equilibrium.

winning one. Mobility also reduced the likelihood that communities would become unanimously restricted or unrestricted (in fact, it never happened in the simulations we ran under the normal rules).

As in the earlier series of simulations, we can ask what happens if local males played according to female change rules and viceversa. The left side of Figure 11 depicts results when the matrix began with an identical distribution to that on the left side of Figure 9, but with the females using male change rules. Once again, there is spatial clustering of males and females with the same strategy, but in this case, the majority of females have switched from a restricted to an unrestricted strategy. Figure 12 (top) depicts those same results temporally. Note that the ratios, identical on the first iteration to those in Figure 10, switch so that

\footnotetext{
${ }^{3}$ Our model also allowed the setting of migration costs. To factor in a cost of migration, we set a threshold such that a neighboring cell would have to offer a sex ratio (number of opposite sex playing current strategy/ total number playing current strategy) that was $25 \%$ greater than the current cell in order for migration to occur. If this threshold was met, an individual would move to the neighboring cell offering the best sex ratio for his or her current strategy.

${ }^{4}$ Once individuals changed strategies, they might be inclined to return to their previous locations, where the ratio relevant to that strategy might be more favorable. However, because other individuals playing the initial strategy might converge on the same spot, and because individuals could not check locations more than one step away, the likelihood of changing strategy could not, from the individual's perspective, be determined before an individual had made a move. Because iterations continued until individuals reached a local optimum, similar final patterns would result if individuals were programmed to change behaviors first, then move.
} 

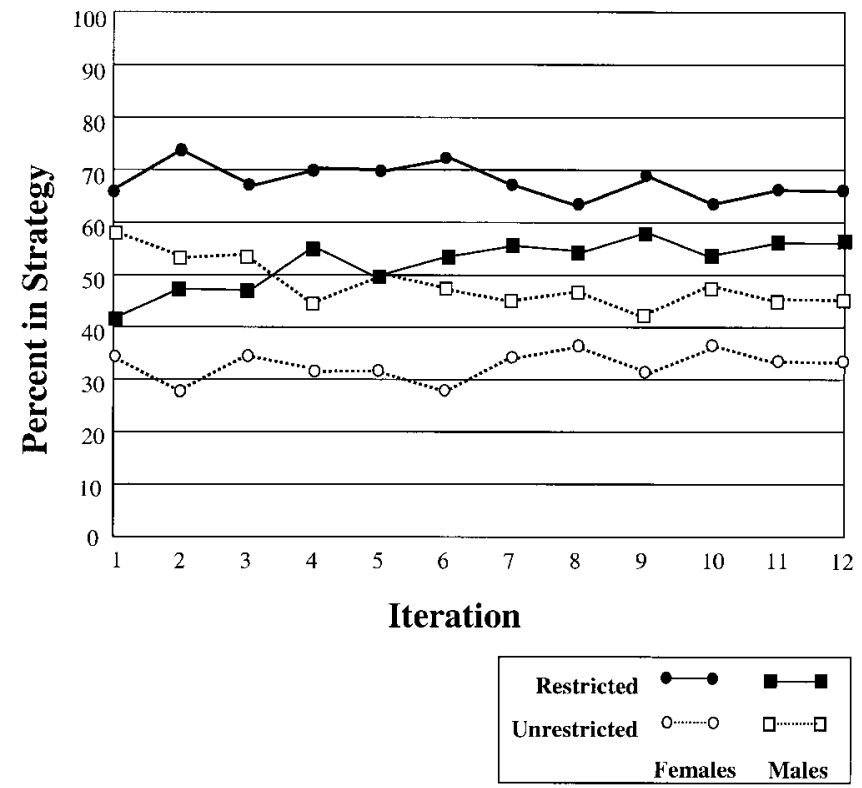

Figure 10. Changes in percentages playing each strategy over iterations, using normal rules.

both sexes predominantly adopt an unrestricted strategy. On average, across communities with the same random placements reported earlier, communities in which females adopt male change rules stabilize with $71 \%$ of the males and $69 \%$ of the females adopting an unrestricted strategy. Another key point is that the small pockets of restricted individuals on the left side of Figure 11 are stable, like the minority pockets in earlier simulations. Once the community reaches stability, local dynamics maintain such minority pockets, as they seem likely to do in real communities.

The right side of Figure 11 shows results from a simulation beginning with the same initial illustrative community but with both sexes playing according to female change rules. On average, networks in which both sexes used female change rules stabilized with $23 \%$ unrestricted males (down from $58 \%$ in the initial values, and comparing to $49 \%$ final ratios when males play by normal rules) and $18 \%$ unrestricted females (down from 33 percent initial values, and comparing to 28 percent when males played by normal rules). Figure 12 (bottom) depicts results over time.

The final set of simulations demonstrates that, even with another level of complexity added, individually based decision rules nevertheless contribute meaningfully to the emergence of spatial selforganization. Indeed, adding mobility to the models demonstrates how a single underlying preference (favoring mates using similar strategies) could contribute to self-organization in more than one way. In some ways, these simulations are reminiscent of Schelling's (1971) analysis of "micromotives and macrophenomena." He used a very simple cellular automaton model (a checkerboard on which dimes and pennies represented members of homogenous groups-men and women or Blacks and Whites, for example) to demonstrate how slight preferences among individuals could lead to unexpectedly profound effects at the group level. For example, even a moderate inclination to want at least some neighbors of one's own race leads to migration patterns that ultimately move integrated communities toward almost complete segregation.

\section{General Discussion}

We began this article with six propositions:

1. Human psychological mechanisms can be conceived as a set of adaptive decision rules.

2. Those decision rules embody conditional strategies designed to serve fundamental motivations associated with key problem areas regularly confronted by our human ancestors.

3. Qualitatively different decision rules are associated with different problem domains.

4. Individuals will differ in decision rules as a function of adaptive design and random variations in trade-offs.

5. Decision mechanisms within any given individual unfold in dynamic interplay with the decision mechanisms of others in his or her social network.

6. Decision mechanisms in different domains have different dynamic implications and sometimes lead to very different sociospatial geometries.

Proposition 1 derives from the fusion of ideas in modern cognitive science and evolutionary biology (Kenrick, 1994; Kenrick, Sadalla, \& Keefe, 1998; Tooby \& Cosmides, 1992). Propositions 2,3 , and 4 follow directly from an emerging body of research and theory within the field of evolutionary psychology (e.g., Bugental, 2000; Cosmides \& Tooby, 1992; Gangestad \& Simpson, 2000; Sherry \& Schacter, 1987). Proposition 5 derives from work in the field of dynamical social psychology (e.g., A. Nowak et al., 1990; Latané \& Bourgeois, 1996). Integrating these perspectives leads logically to Proposition 6. There are a number of wideranging implications of this integration, and the simulations presented here were designed to illustrate some of those implications.

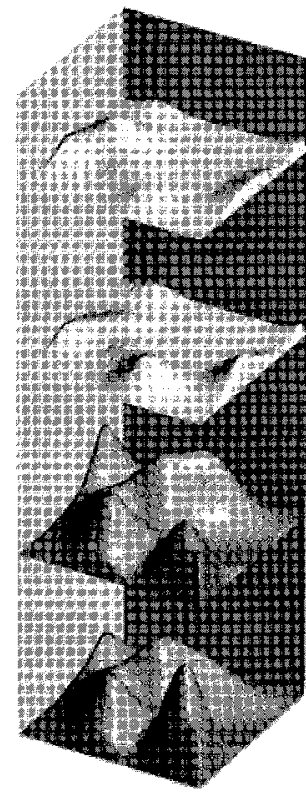

Equilibrium-Male Rules

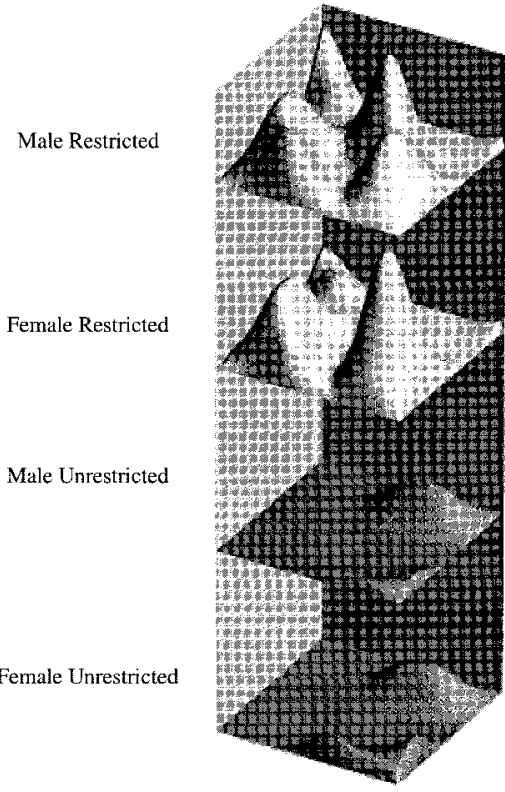

Equilibrium—Female Rules
Figure 11. Left: Location of restricted and unrestricted individuals at equilibrium, when initial arrangement was the same as Figure 9, but all individuals played according to male change rules. Right: Arrangement at equilibrium when all played according to female change rules. 

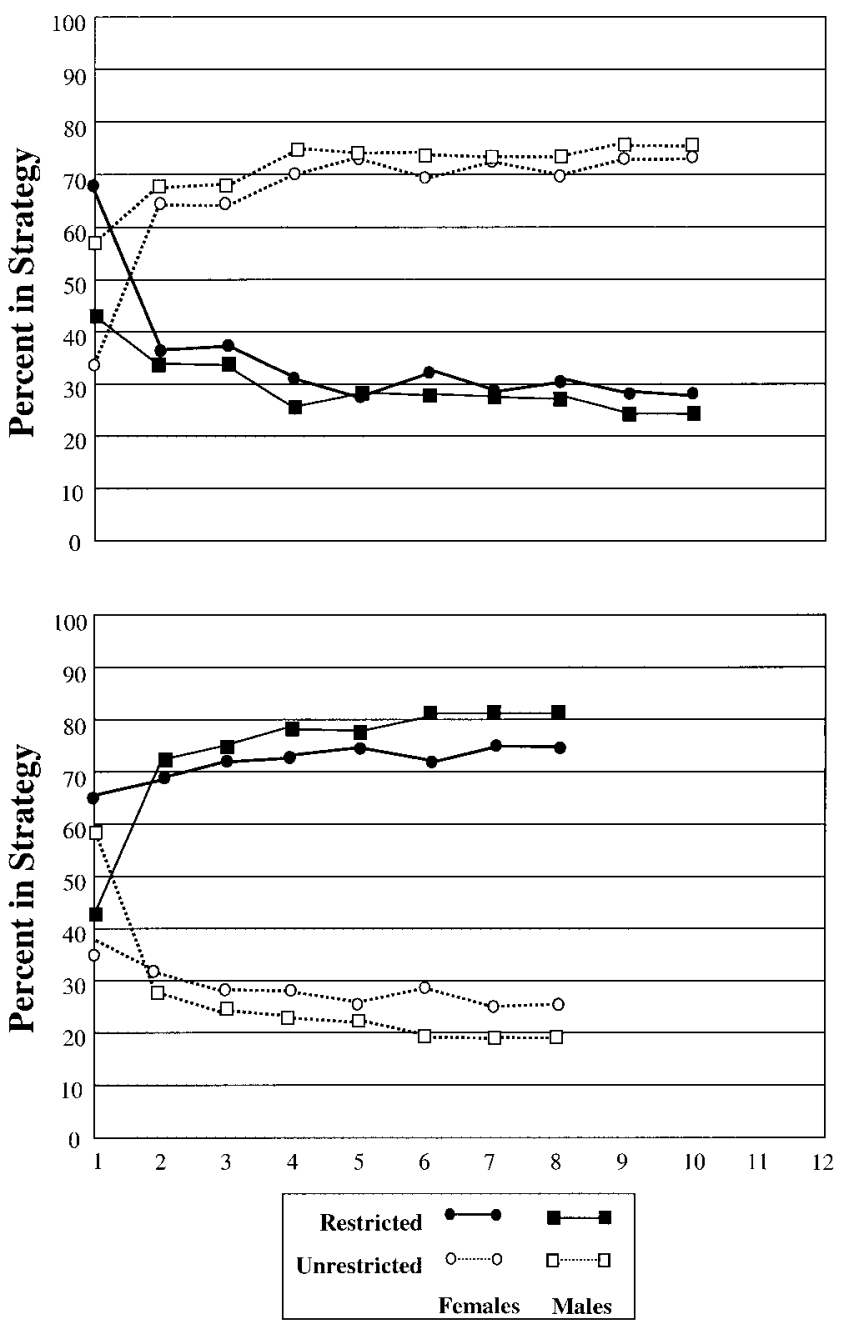

Figure 12. Top panel shows changes in percentages playing each strategy over iterations with male rules only. Bottom panel shows changes over iterations with female rules only.

A key point of the simulations is that individual differences in adaptive decision rules-the domain of evolutionary psychology-can have critical implications for social dynamics at the community level-the domain of dynamical systems theory. A very small minority of individuals set to a different threshold for hostility, for example, can completely transform the outcomes for the majority of their neighbors from peacefulness to hostility. A local population of females playing by more male-like unrestricted rules completely changes the dynamics for the males in their vicinity, even though the males themselves do not change their underlying mating decision rules. Further, the impact of individual differences depends on the state of the system. By systematically varying control parameters, it is possible to determine the conditions under which individual differences and initial spatial arrangements will be relatively more or less important.

\section{The Evolution of Evolutionary Psychology}

How does a dynamical approach go beyond traditional evolutionary psychological approaches? Natural selection involves a process in which the physiological and behavioral characteristics of organisms are brought into attunement with the demands and opportunities provided by the environment. For this reason, evolutionary approaches to behavior have implicitly incorporated notions of organism-environment interactions (Crawford \& Anderson, 1989; Janicki \& Krebs, 1998; Kenrick, 1987). However, the extent to which these interactions have been explicitly considered has evolved over the years.

Early evolutionary psychological models tended to devote primary attention to innate predispositions that differentiated males and females, for example, or individuals adopting restricted or unrestricted mating strategies, without explicitly considering how those predispositions might interact with particular environmental factors (e.g., Sadalla et al., 1987; E. O. Wilson, 1975). Although certain sex differences, such as the physiological capacity to bear and nurse offspring, are constants, their implications for behaviors will vary depending on factors in the physical and social environment, such as availability of resources and population sex ratios (Crook \& Crook, 1988; Daly \& Wilson, 1983; Guttentag \& Secord, 1983). Evolutionary models have given increasingly explicit attention to the ways in which innate predispositions might interact with events in the environment to produce either long-term or short-term changes in behavior (e.g., Draper \& Belsky, 1990; Gangestad \& Simpson, 2000; Kenrick, et al., 1990). For example, the biosocial interactionist model of gender differences considers several ways in which differential genetic predispositions in females and males might affect, and be affected by, the social environment (Kenrick, 1987). Work on a qualified parental investment model (Kenrick et al., 1990, 1993) explored how male and female criteria for mates can be identical or different depending on the amount of resources invested in a relationship. The sexes differ very little when considering marital partners, for example, but greatly when considering partners for sexual relationships (Kenrick et al., 1990, 1993). Buss and Schmitt's (1993) sexual strategies theory likewise considers circumstances under which men and women opt for short-term versus long-term approaches to mating. Gangestad and Simpson's (2000) strategic pluralism model also explicitly explores how varying circumstances affect trade-offs between expending time and energy on mating versus child rearing, thereby influencing the development of individual differences in restricted or unrestricted mating strategies.

A dynamical evolutionary approach moves beyond previous interactionist evolutionary approaches in at least two important ways. First, it explicitly focuses attention on the web of mutual influences connecting any given individual to the other individuals in his or her community. Psychologists adopting an evolutionary perspective have tended to shine the spotlight on the individual and, occasionally, the dyad. Yet competitive and mating decisions necessarily take place between interconnected webs of individuals. Implicit acknowledgment of an interactive web is not enough, because the specifics of what goes on in that web, and where, often completely change the contingencies for the individual or the dyad (see also Killingback \& Doebeli, 1996). Second, a dynamical approach inspires an explicit quantitative specification of individual decision rules and population ratios. Although we have achieved some important advances using broad general assumptions, dynamical simulations make it clear that initially small variations in decision rules and in population ratios often magnify into large effects at the community level. 
Finally, there is one counterintuitive benefit of taking this step up in the complexity of existing models. By incorporating an understanding of self-organization, more complex dynamical models can ultimately help simplify the understanding of previously mystifying interactions. Dynamic analyses of complex networks throughout the natural world have revealed that intrinsically disorganized and chaotic interactions often move toward "order for free," in the sense of self-maintaining patterns that emerge spontaneously from very simple component processes (Kauffman, 1995).

\section{Evolutionizing Dynamical Approaches to Behavior}

Dynamical systems approaches have been fruitfully applied to a number of domains of social behavior in recent years (Latané, 1996; A. Nowak, et al., 2000; A. Nowak \& Vallacher, 1998). The work reported here is in some ways an extension of Latané's work on dynamic social influence processes in groups (Latané, 1996; Latané \& L'Herrou, 1996). Explicitly incorporating evolutionary psychological concepts extends the previous work in at least two important ways. First, an evolutionary dynamic approach focuses attention on the particulars of individual differences. As we have shown, individual differences in decision rules can have profound consequences for network dynamics. Second, an evolutionary dynamic approach focuses attention on the importance of content. Research on dynamical systems has tended to focus on general processes such as self-organization-a process found in systems at all levels of complexity, from molecules to ecosystems (Lewin, 1993; Kauffman, 1995). Awareness of such general processes represents an important advance in our understanding of the natural world. However, researchers who study living organisms are concerned with the particular forms of self-organization that emerge from the specific decision rules instantiated in particular types of organisms. Because humans are the product of a particular evolutionary history, and live in societies created and maintained by other members of this particular species, it is important to focus our models on the critical decision domains likely to be important to individual human beings in human social groups. As discussed earlier, there are likely to be very different default settings for making decisions in different realms. These different decision rules are likely to have different implications for the geometry of networks and, consequently, different dynamic outcomes. Evolutionarily informed models of adaptive decision making can provide useful clues about the specifics of those differences.

\section{Gene-Culture Interactions}

The demonstrations of self-organization presented here help illustrate why person-environment interactions, despite the random vagaries of multitudinous inputs, often tend toward reliable and self-maintaining patterns. Incorporating notions of selforganization into our models of organism-environment interactions could provide a new way to understand how social norms emerge systematically out of the information-processing mechanisms of the individuals who interact within natural communities (see Latané, 1996; Schaller \& Latané, 1996). In this light, selforganization may have important implications for understanding gene-culture interactions-how societal regularities emerge out of interactions between the individuals who compose societies
(Fiske, Kitayama, Markus, \& Nisbett, 1998; Lumsden \& Wilson, 1981; Tooby \& Cosmides, 1992). To this view, culture is not a phenomenon outside the stream of human evolution but an emergent dynamic that interacts with the decision rules of the individuals who make up societies. A combination of evolutionary and dynamic insights could allow us to move toward a more precise specification of how cultures and individuals mutually construct and constrain one another.

Spatial simulations allow us to explore how variations in local norms can arise and persist, even when individuals are assumed to have fairly inflexible innate decision rules (Tooby \& Cosmides, 1990). ${ }^{5}$ These simulations can thus provide an important bridge between the individual-level analysis of traditional sociobiology and the sociocultural level of analysis of the traditional social sciences. Consider our mating simulations, in which initially randomly distributed groups of males and females converged on communities where most individuals behaved in a restricted manner and local subpopulations engaged in unrestricted behavior. These locally self-maintaining norms for sexual behavior were not built directly into the system but emerged bottom-up from decision rules in individuals (all of whom could have behaved in either way, depending on their circumstances). In these simulations, based on preliminary estimates of current preferences in American college students, female choice at the individual level had a marked effect on the norms that emerged. Indeed, network dynamics resulted, not in an averaging of the two sexes' initial preferences, but in a tipping of the scale, so that norms in final communities favored restricted behavior more strongly than the preferences of either sex would have led us to predict at the outset.

Historically, sociocultural models have focused on the seemingly random and arbitrary nature of cultural norms (for a review, see Tooby \& Cosmides, 1992). Some of the local subcultural pockets emerging in these simulations did in fact result from random configurations of initial members. However, the arrays of individual choices that contribute to the emergence of cultural norms are not randomly chosen from the universe of possibilities but from those compatible with the range of preferences and proclivities of members of this particular species. This highlights again the importance of an interplay between model building and empirical data that reflect on likely decision rules. Our models will be more fruitful to the extent that they incorporate decision rules reflecting the actual psychology of Homo sapiens, which is itself the product of millions of years of random variation and selective retention.

We note above that migration in search of mates may be more characteristic of the modern world than of the conditions under which our ancestors evolved their preferences. In this regard, it is worth noting that simulations can help explore how changes in an aspect of culture or ecology are likely to interact with ancestrally

\footnotetext{
${ }^{5}$ Evolutionary theorists believe that many, if not most, behavioral characteristics in humans and other vertebrates are more complex than this and represent an interplay of underlying predispositions, developmental experiences, and current environmental contingencies (e.g., Alcock, 1998a, 1998b; Buss et al., 1998; Gross, 1996; Kenrick, 1987). These data show, however, that complexity and flexibility at the phenotypic level can emerge even if one assumed underlying if-then mechanisms that do not themselves change with experience (Tooby \& Cosmides, 1990).
} 
based decision rules to lead to different emergent processes at the societal level. Thus, as psychologists develop more complete models, it should be possible to use dynamical simulations to make more educated guesses about outcomes that might follow from the interaction of human decision processes and proposed social interventions.

\section{Evolved Psychological Mechanisms Involve Dynamics at Several Levels of Analysis}

Our consideration of gene-culture interactions highlights an important point: There are important mutual questions involving evolution and dynamics from microscopic to macroscopic levelsfrom genes to cells to organisms to ecosystems. At the microscopic level, the most important environment for any given gene is the set of other genes in the same organism (Dawkins, 1982, 1986; Kauffman, 1995). Genes must work together to produce a functioning phenotype - an organism with component parts that themselves work together (Tooby \& Cosmides, 1990). That organism must mesh with other organisms in an ecosystem (Caporael \& Baron, 1997). For example, forests of sea kelp provide support for other algae, crustaceans, squid, and fishes, all of which began to disappear when otters were hunted to near extinction off the Pacific coast of North America. The kelp plants disappeared because they were eaten by sea urchins, which were previously kept in check by the otters, who themselves eat the urchins (E. O. Wilson, 1992). When the kelp colonies disappeared, so did many other species linked in any way to them. This illustrates the more general point that each species is dynamically interconnected with the others in its habitat.

Dynamics at each level of analysis can also be considered across time. Over generations, genes are selected if they are compatible with the collection of other genes making up a prototypical member of a given species and if they together produce organisms with characteristics promoting survival within the dynamic context of other organisms in current environments. Considered in a more distal perspective, the assemblies of genes that make up today's living organisms are those that constructed organisms capable of surviving in past environments.

With regard to broader questions about natural selection, we have focused here on the level of analysis that has historically been most relevant to social psychology - that of individuals interacting with one another in the current environment. In line with the above reasoning, this general way of thinking has implications for the other levels of analysis. At the ontogenetic level, for example, individual-level decision rules both contribute to and are influenced by the social dynamics within which an individual develops. At the phylogenetic level, social dynamics affect and are affected by the distribution of genes involved in the development of behavioral, affective, and cognitive mechanisms (Kenrick, 1987; Tooby \& Cosmides, 1992). Evolutionary game theorists have used dynamical networks to examine the evolution of adaptive mechanisms over time (e.g., Killingback \& Doebeli, 1996; M. A. Nowak \& May, 1992; Sella \& Lachmann, 2000). These studies have typically involved simulations similar to those in our first series, in which individuals are linked to contiguous neighbors in an iterated version of a prisoner's dilemma or Hawk-Dove game. Natural selection is introduced to the system as more successful individuals reproduce and replace less successful ones. In contrast to the studies we presented here, which began with a set of decision rules and examined how group-level phenomena might emerge from them, evolutionary game theorists have used spatial simulations to understand which decision rules would be relatively more or less adaptive within populations across generations. Thus far, such simulations have been conducted mainly by mathematicians and biologists, but they provide yet another tool to expand evolutionary psychological analyses. Reciprocally, psychological research, by providing evidence regarding the operation of existing mechanisms, can help educate guesses about plausible assumptions for such models. These issues of different levels of analysis have been addressed in more detail elsewhere (Kenrick, Maner, et al., 2002).

\section{Limitations}

Rather than starting with a complex phenomenon and attempting to break it down into its smallest operating units, as one would do when approaching a problem using experimental methods in the analytic-reductionist mode, the approach taken here began with simple units (decision rules) and used computer simulations to observe how these might unfold in a more complex dynamic system, given some assumptions about the social geometry within which people influence one another. As discussed earlier, computer simulations have added another useful step into the traditional cycle of science. They are not an alternative to the use of other research techniques; experimental research, survey research, archives, and cross-cultural studies are essential for establishing the existence and operation of plausible decision-making mechanisms. Simulations simply help explore how component elements contribute to dynamic patterns that cannot be observed with the usual analytic approaches (Holland, 1998; A. Nowak \& Vallacher, 1998).

These simulations thus provide results that are intrinsically limited in ecological validity but that raise a number of fruitful implications. Using a full-cycle approach, other types of empirical data can be used to educate the decision rules built into those models and to explore the validity of model outcomes. Researchers might examine dynamics within large naturalistic data sets, for example, considering how marriage and crime statistics change over time as a function of local age and sex ratios, kinship relations, or temporal variations in economic conditions. For researchers who have focused on individual decision-making, network models can suggest interesting processes that might emerge from those decisions among individuals connected in webs with different geometries. In certain settings, such as business, military, and college, it may be possible to experimentally combine particular groups of individuals into prearranged networks to examine the dynamic implications of particular individual differences on the group as a whole. Naturalistic studies of mating dynamics or the emergence of status hierarchies in "captive" groups, such as the freshman students at a small campus or the employees in a new office, may be a particularly fruitful way to examine the mutual effects of individual differences and network-level dynamics. In keeping with our discussion above, results of such naturalistic and experimental studies could be used in tandem with simulations that would help home in on key parameters, decision rules, and emergent processes.

In the simulations presented here, we considered only a small subset of the implications suggested by the model we outlined 
earlier. We did not model processes related to status, mate retention, intergroup protection, or parenting, for example, each of which was hypothesized to have a different social geometry and attendant different dynamics. Again, simulations ought to go hand in hand with research examining these different geometries in natural groups. Variations of sociometric and social support network analyses could be useful in verifying or refining our hypotheses about the social geometries associated with each domain. Additional interesting questions involve the relationship between these hypothesized social geometries and the spatial geometries considered by Latané and colleagues (Latané \& Bourgeois, 1996; Latané \& Liu, 1996).

One question about the models presented here concerns the frequency with which people update behavioral strategies based on social inputs. We expect that this will vary by domain. For example, if others are cheating you or cheating on you, then over time there will be strong pressure to develop mechanisms that are sensitive to this and that respond quickly to changes in the social environment. There is evidence that people respond within milliseconds to certain types of potential threats and opportunities in their environment-such as angry faces or flirtatious glances (Eibl-Eibesfeldt, 1972; Hansen \& Hansen, 1988). Decisions about friendly coalitions, on the other hand, probably do not require such rapid and frequent updates. Ironically, attitude change, where much of the previous work on social dynamics has been done, may not have been the best place to begin, because people may not update their opinions as frequently as they update in other domains of social behavior (such as mating opportunities or threats).

In our first series of simulations, the initial ratio of individuals behaving in one way or the other was 50/50. When there are no low-threshold individuals, this will tend to produce more "multistable" systems, in which the social equilibrium can tip either way, depending on random spatial locations in the initial array (as noted in Figure 5). However, the initial proportion of individuals acting aggressively or peacefully makes less of a difference as the number of low-threshold individuals increases. This suggests that the importance of initial ratios and random spatial distributions will matter differently depending on the decision rules coming into play and will thus vary in a given domain of social life. For example, people are likely to have more cautious decision rules for domains where false negatives or positives have greater cost (as in trusting a potentially hostile out-group member or an unfaithful spouse), and more tolerant decision rules where potential costs are lower (as in sharing resources with a closely related in-group member).

As noted earlier, researchers adopting an evolutionary perspective agree on a number of broad themes but offer a range of viable hypotheses regarding exactly how these broad theoretical models apply to human beings. There are diverse hypotheses about the precise parameters of male and female mating strategies, for example (e.g., Gangestad \& Simpson, 2000; Hazan \& Diamond, 2000; Hrdy, 1999). As we saw in the simulations, differences in decision rules can sometimes be magnified into much larger effects at the community level. This again highlights the importance of a full-cycle approach, in which intuitive theory, computerassisted modeling, and diverse forms of empirical data are all used to converge on increasingly complete understanding.

The simulations here modeled decisions as "all-or-none" choices. Latané and Nowak (1994) reviewed evidence to suggest that all-or-none decision rules increase with more important topics. As discussed above, an evolutionary perspective can offer some suggestions about which domains of decision making are likely to be psychologically important ones. It is important to note that similar processes of spatial self-organization occur even with more continuous decision rules (Latané, 1996). For example, we re-ran our aggression simulations using four rather than two levels of hostility-peacefulness. Those simulations revealed some movement toward central values (twos and threes versus ones and fours). At the same time, the same sorts of spatially contiguous pockets shown in Figure 3 formed once again, this time on either side of middle opinion (much like what happened in the U.S. presidential election in 2000, when views just to the left and right side of the middle became intensely polarized).

There is some controversy about the extent to which natural selection must occur incrementally or is given a boost by selforganizational processes of the sort we have discussed here (Dawkins, 1986; Goodwin, 1994; Kauffman, 1995). It is important to note that evolutionary theorists agree that natural selection is necessary to sculpt complex functional traits, such as the bat's "sonar" system, or the human visual system (which includes cofunctioning retina, lens, cornea, optical nerve, and visual cortex linked to perception and response systems in an integrated way; Alcock, 1998b; Buss, Haselton, Shackelford, Bleske, \& Wakefield, 1998; Dawkins, 1986). The importance of natural selection in the development and persistence of such complex systems is attested to by their disappearance when selection pressures change, as illustrated by the fact that mammals, fish, and insects that live in caves are often blind, even though their surface-dwelling ancestors had complex visual systems.

Dynamical systems theorists, as the ultimate antireductionists, are sometimes wary of reductionism in evolutionary biology (e.g., Dawkins, 1976; E. O. Wilson, 1998). However, evolutionary biologists have incorporated a number of inherently dynamic concepts, such as frequency-dependent selection. Indeed, modern evolutionary theory coevolved with ecology, a field explicitly concerned with dynamical processes. Changes in a given gene can have systemwide ramifications, but those effects always work through interactions with other genes and via the construction of cells that interact with other cells to construct organs that interact with organs, and so on through the level of complex organisms interacting with other complex organisms in self-organizing ecosystems (Caporael \& Baron, 1997; Dawkins, 1986). Thus, a dynamical evolutionary position hardly implies that all psychologists should begin to search for isolated genes. On the other hand, because dynamical processes at one level often emerge bottom-up from decision rules affecting behavior at lower levels, this approach also counsels against a content-free holism that eschews any analysis of system components. Even single genes can have effects on the whole system of genes and, ultimately, on the development and behavior of the organism (Ridley, 2000; Weiner, 1999). The field of psychology is probably best served by dogmatically embracing neither a reductionism that ignores emergent processes nor a holism that ignores the substrate out of which higher level patterns emerge. Instead, a full understanding of adaptive problems faced by complex organisms living in groups of other complex organisms will come from simultaneous consideration of multiple levels of causality. 


\section{The Promise of a Dynamical Evolutionary Psychology}

Thus far, the evolutionary perspective has yielded productive insights regarding a number of behavioral domains, including altruism, aggression, learning, decision making, and sex differences in mating behavior (Alcock, 2001; Barkow, Cosmides, \& Tooby, 1992; Buss \& Kenrick, 1998, Crawford \& Krebs, 1998; Daly \& Wilson, 1983, 1988; Seligman \& Hager, 1972). There have been some theoretical forays into the realm of group processes (e.g., Caporael \& Baron, 1997; Krebs \& Denton, 1997; Neuberg, Smith, \& Asher, 2000; D. S. Wilson, 1997) but less empirical work. We suspect that such empirical work will be more fruitful to the extent that these forays are elucidated by a consideration of network dynamics. The models we have presented here support the assumption of theorists who argue that individual psychological mechanisms of the sort studied by evolutionary psychologists will interact to produce nonlinear and self-organizing emergent processes (e.g., Baron \& Misovich, 1999; Schaller \& Latané, 1996).

Twenty years ago it seemed reasonable to ask whether evolutionary models of human behavior would yield empirical fruit. Evolutionary psychologists thought the prospects good, given the success of such models applied to other animal species. Today, an abundant body of research and theory attests to the heuristic potential of this enterprise (Alcock, 2001; Buss, 1999; Crawford \& Krebs, 1998; Kenrick \& Trost, 1997; Tooby \& Cosmides, 1992). Are there likely to be further heuristic benefits from expanding those horizons to encompass developments in dynamical systems theory? Given the progress made by complexity theorists toward understanding a wide range of animate and inanimate systems, we believe that a further broadening of both enterprises into a dynamical evolutionary psychology can only prove productive and enlightening.

\section{References}

Agosta, W. C. (1992). Chemical communication. New York: Scientific American.

Alcock, J. (1998a). Animal behavior: An evolutionary approach (6th ed.). Sunderland, MA: Sinauer Associates.

Alcock, J. (1998b). Unpunctuated equilibrium in the Natural History essays of Stephen Jay Gould. Evolution and Human Behavior, 19, 321-336.

Alcock, J. (2001). The triumph of sociobiology. New York: Oxford University Press.

Baer, D., \& McEachron, D. L. (1982). A review of selected sociobiological principles: Application to hominid evolution I: The development of group social structure. Journal of Social and Biological Structures, 5, 69-90.

Bailey, J. M., Gaulin, S., Agyei, Y., \& Gladue, B. A. (1994). Effects of gender and sexual orientation on evolutionarily relevant aspects of human mating psychology. Journal of Personality and Social Psychology, 66, 1081-1093.

Barkow, J. H., Cosmides, L., \& Tooby, J. (1992). The adapted mind. New York: Oxford University Press.

Baron, R. M., \& Misovich, S. J. (1999). On the relationship between social and cognitive modes of organization. In S. Chaiken \& Y. Trope (Eds.), Dual-process theories in social psychology (pp. 586-605). New York: Guilford Press.

Baumeister, R. F., \& Leary, M. R. (1995). The need to belong: Desire for interpersonal attachments as a fundamental human motivation. Psychological Bulletin, 117, 497-529.
Bell, A. P., \& Weinberg, M. S. (1978). Homosexualities: A study of diversity in men and women. New York: Simon \& Schuster.

Bossard, J. H. S. (1932). Residential propinquity as a factor in marriage selection. American Journal of Sociology, 38, 219-224.

Brechner, K. C. (1977). An experimental analysis of social traps. Journal of Experimental Social Psychology, 13, 552-564.

Brehm, S. S. (1992). Intimate relationships (2nd ed.). New York: McGrawHill.

Brewer, M. B., \& Lui, L. N. (1989). The primacy of age and sex in the structure of person categories. Social Cognition, 3, 262-274.

Bugental, D. B. (2000). Acquisition of the algorithms of social life: A domain-based approach. Psychological Bulletin, 126, 187-219.

Burnstein, E., Crandall, C., \& Kitayama, S. (1994). Some neo-Darwinian rules for altruism: Weighing cues for inclusive fitness as a function of the biological importance of the decision. Journal of Personality and Social Psychology, 67, 773-789.

Buss, D. M. (1995). Evolutionary psychology: A new paradigm for psychological science. Psychological Inquiry, 6, 1-30.

Buss, D. M. (1999). Evolutionary psychology: The new science of mind. Boston: Allyn \& Bacon.

Buss, D. M., Haselton, M. G., Shackelford, T. K., Bleske, A. L., \& Wakefield, J. C. (1998). Adaptations, expatations, and spandrels. American Psychologist, 53, 533-548.

Buss, D. M., \& Kenrick, D. T. (1998). Evolutionary social psychology. In D. T. Gilbert, S. T. Fiske, \& G. Lindzey (Eds.), Handbook of social psychology (Vol. 2, 4th ed., pp. 982-1026). New York: McGraw-Hill.

Buss, D. M., Larsen, R. J., Westen, D., \& Semmelroth, J. (1992). Sex differences in jealousy: Evolution, physiology, and psychology. Psychological Science, 2, 204-232.

Buss, D. M., \& Schmitt, D. (1993). Sexual strategies theory: An evolutionary perspective on human mating. Psychological Review, 100, $204-$ 232.

Caporael, L. R., \& Baron, R. M. (1997). Groups as the mind's natural environment. In J. A. Simpson \& D. T. Kenrick (Eds.), Evolutionary social psychology (pp. 317-344). Mahwah, NJ: Erlbaum.

Cavalli-Sforza, L. L., \& Cavalli-Sforza, F. (1995). The great human diasporas: The history of diversity and evolution. Reading, MA: Addison-Wesley.

Cialdini, R. B. (1995). A full-cycle approach to social psychology. In G. C. Brannigan \& M. R. Merrens (Eds.), The social psychologists: Research adventures (pp. 52-73). New York: McGraw-Hill.

Cosmides, L., \& Tooby, J. (1992). Cognitive adaptations for social exchange. In J. H. Barkow, L. Cosmides, \& J. Tooby (Eds.), The adapted mind (pp. 163-228). New York: Oxford University Press.

Cosmides, L., Tooby, J., \& Barkow, J. H. (1992). Introduction: Evolutionary psychology and conceptual integration. In J. H. Barkow, L. Cosmides, \& J. Tooby (Eds.), The adapted mind (pp. 3-18). New York: Oxford University Press.

Crawford, C. (1998). The theory of evolution in the study of human behavior: An introduction and overview. In C. Crawford \& D. L. Krebs (Eds.), Handbook of evolutionary psychology (pp. 3-42). Mahwah, NJ: Erlbaum.

Crawford, C. B., \& Anderson, J. L. (1989). Sociobiology: An environmentalist discipline. American Psychologist, 44, 1449-1459.

Crawford, C., \& Krebs, D. L. (1998). Handbook of evolutionary psychology. Mahwah, NJ: Erlbaum.

Crook, J. H., \& Crook, S. J. (1988). Tibetan polyandry: Problems of adaptation and fitness. In L. Betzig, M. Borgerhoff-Mulder, \& P. Turke (Eds.), Human reproductive behavior: A Darwinian perspective (pp. 97-114). Cambridge, England: Cambridge University Press.

Cunningham, M. R., Druen, P. B., \& Barbee, A. P. (1997). Angels, mentors, and friends: Tradeoffs among evolutionary, social, and individual variables in physical appearance. In J. Simpson \& D. T. Kenrick 
(Eds.), Evolutionary social psychology (pp. 109-141). Hillsdale, NJ: Erlbaum.

Daly, M. (1989). Parent-offspring conflict and violence in evolutionary perspective. In R. W. Bell \& N. J. Bell (Eds.), Sociobiology and the social sciences (pp. 25-44). Lubbock: Texas Tech University Press.

Daly, M., Salmon, C., \& Wilson, M. (1997). Kinship: The conceptual hole in psychological studies of social cognition and close relationships. In J. A. Simpson \& D. T. Kenrick (Eds.), Evolutionary social psychology (pp. 265-296). Mahwah, NJ: Erlbaum.

Daly, M., \& Wilson, M. (1983). Sex, evolution, and behavior (2nd ed.). Boston: Willard Grant Press.

Daly, M., \& Wilson, M. (1988). Homicide. Hawthorne, NY: Aldine de Gruyter.

Dawkins, R. (1976). The selfish gene. Oxford, England: Oxford University Press.

Dawkins, R. (1982). The extended phenotype. Oxford, England: Oxford University Press.

Dawkins, R. (1986). The blind watchmaker. New York: Norton.

Diamond, J. (1997). Guns, germs, and steel. New York: Norton.

Dijkstra, P., \& Buunk, B. P. (1998). Jealousy as a function of rival characteristics: An evolutionary perspective. Personality and Social Psychology Bulletin, 24, 1158-1166.

Draper, P., \& Belsky, J. (1990). Personality development in evolutionary perspective. Journal of Personality, 58, 141-162.

Eibl-Eibesfeldt, I. (1972). Similarities and differences between cultures in expressive movements. In R. A. Hinde (Ed.), Non-verbal communication (pp. 297-312). London: Cambridge University Press.

Emlen, S. T., Wrege, P. H., \& DeMong, N. J. (1995). Making decisions in the family: An evolutionary perspective. American Scientist, 83, 148157.

Endler, N. S., \& Magnusson, D. (1976). Interactional psychology and personality. Washington, DC: Hemisphere.

Essock-Vitale, S. M., \& McGuire, M. T. (1985). Women's lives viewed from an evolutionary perspective. II: Patterns of helping. Ethology and Sociobiology, 6, 155-173.

Essock-Vitale, S. M., \& McGuire, M. T. (1989). Social and reproductive histories of depressed and anxious women. In R. W. Bell \& N. Bell (Eds.), Sociobiology and the social sciences (pp. 105-118). Lubbock: Texas Tech University Press.

Fiske, A. P. (1992). The four elementary forms of sociality: Framework for a unified theory of social relations. Psychological Review, 99, 689-723.

Fiske, A. P., Kitayama, S., Markus, H. R., \& Nisbett, R. E. (1998). The cultural matrix of social psychology. In D. T. Gilbert, S. T. Fiske, \& G. Lindzey (Eds.), Handbook of social psychology (4th ed., pp. 915-982). New York: McGraw-Hill.

Gangestad, S. W., \& Simpson, J. A. (1990). Toward an evolutionary history of female sociosexual variation. Journal of Personality, 58, $69-96$.

Gangestad, S. W., \& Simpson, J. A. (2000). The evolution of human mating: Trade-offs and strategic pluralism. Behavioral and Brain Sciences, 23, 573-587.

Garcia, J., \& Koelling, R. A. (1966). Relation of cue to consequence in avoidance learning. Psychonomic Science, 4, 123-124.

Gardner, H. (1985). The mind's new science: A history of the cognitive revolution. New York: Basic Books.

Geary, D. C. (1998). Male, female: The evolution of human sex differences. Washington, DC: American Psychological Association.

Geary, D. C. (2000). Evolution and proximate expression of human paternal investment. Psychological Bulletin, 126, 55-77.

Glass, A. L., \& Holyoak, K. J. (1986). Cognition (2nd ed.). New York: Random House.

Goodwin, B. (1994). How the leopard changed its spots. New York: Scribner.

Graziano, W. G., Jensen-Campbell, L. A., Todd, M., \& Finch, J. F. (1997).
Interpersonal attraction from an evolutionary perspective: Women's reactions to dominant and prosocial men. In J. A. Simpson \& D. T. Kenrick (Eds.), Evolutionary social psychology (pp. 141-168). Mahwah, NJ: Erlbaum.

Griffin, D. R. (1958). Listening in the dark. New Haven, CT: Yale University Press.

Gross, M. R. (1996). Alternative reproductive strategies and tactics: Diversity within sexes. Trends in Ecology and Evolution, 11, 92-98.

Gutierres, S. E., Kenrick, D. T., \& Partch, J. J. (1999). Beauty, dominance, and the mating game: Contrast effects in self-assessment reflect gender differences in mate selection. Personality and Social Psychology Bulletin, 25, 1126-1135.

Guttentag, M., \& Secord, P. F. (1983). Too many women? The sex ratio question. Beverly Hills, CA: Sage Publications.

Haley, M. P., Deutsch, C. J., \& LeBoeuf, B. J. (1994). Size, dominance, and copulatory success in male elephant seals, Mirounga angustirostris. Animal Behaviour, 48, 1249-1260.

Hamilton, W. D. (1964a). The genetical evolution of social behaviour: I. Journal of Theoretical Biology, 7, 1-16.

Hamilton, W. D. (1964b). The genetical evolution of social behaviour: II. Journal of Theoretical Biology, 7, 17-52.

Hansen, C. H., \& Hansen, R. D. (1988). Finding the face in the crowd: An anger superiority effect. Journal of Personality and Social Psychology, 54, 917-924.

Hastie, R., \& Park, B. (1986). The relationship between memory and judgment depends on whether the judgment task is memory-based or on-line. Psychological Review, 93, 258-268.

Hazan, C., \& Diamond, L. M. (2000). The place of attachment in human mating. Review of General Psychology, 4, 186-204.

Hettema, J., \& Kenrick, D. T. (1992). Models of person-situation interactions. In G. V. Caprara \& G. L. vanHeck (Eds.), Modern personality psychology: Critical reviews and new directions (pp. 393-417). New York: Harvester Wheatsheaf.

Hill, K., \& Hurtado, A. M. (1993). Hunter-gatherers of the New World. In P. W. Sherman \& J. Alcock (Eds.), Exploring animal behavior (pp. 154-160). Sunderland, MA: Sinauer.

Hill, K., \& Hurtado, A. M. (1996). Ache life history. Hawthorne, NY: Aldine deGruyter.

Hoffman, L. W., \& Manis, J. D. (1978). Influences of children on marital interaction and parental satisfactions and dissatisfactions. In R. M. Lerner \& G. B. Spanier (Eds.), Child influences on marital and family interaction (pp. 165-213). New York: Academic Press.

Holland, J. H. (1998). Emergence: From chaos to order. Reading, MA: Addison-Wesley.

Hrdy, S. H. (1999). Mother Nature: A history of mothers, infants, and natural selection. New York: Pantheon.

Huguet, P., Latané, B., \& Bourgeois, M. (1998). The emergence of a social representation of human rights via interpersonal communication: Empirical evidence for the convergence of two theories. European Journal of Social Psychology, 28, 831-846.

Janicki, M., \& Krebs, D. L. (1998). Evolutionary approaches to culture. In C. Crawford \& D. L. Krebs (Eds.), Handbook of evolutionary psychology (pp. 163-208). Mahwah, NJ: Erlbaum.

Kauffman, S. (1995). At home in the universe: The search for the laws of self-organization and complexity. New York: Oxford University Press.

Kenrick, D. T. (1987). Gender, genes, and the social environment: A biosocial interactionist perspective. In P. Shaver \& C. Hendrick (Eds.), Review of personality and social psychology (Vol. 7, pp. 14-43). Newbury Park, CA: Sage.

Kenrick, D. T. (1994). Evolutionary social psychology: From sexual selection to social cognition. In M. P. Zanna (Ed.), Advances in experimental social psychology (Vol. 26, pp. 75-122). San Diego, CA: Academic Press. 
Kenrick, D. T. (1995). Evolutionary theory versus the confederacy of dunces. Psychological Inquiry, 6, 56-61.

Kenrick, D. T., \& Dantchik, A. (1983). Interactionism, idiographics, and the social psychological invasion of personality. Journal of Personality, 51, 275-285.

Kenrick, D. T., \& Funder, D. C. (1988). Profiting from controversy: Lessons of the person-situation debate. American Psychologist, 43, 23-24.

Kenrick, D. T., Gabrielidis, C., Keefe, R. C., \& Cornelius, J. (1996). Adolescents' age preferences for dating partners: Support for an evolutionary model of life-history strategies. Child Development, 67, 14991511.

Kenrick, D. T., Groth, G. E., Trost, M. R., \& Sadalla, E. K. (1993). Integrating evolutionary and social exchange perspectives on relationships: Effects of gender, self-appraisal, and involvement level on mate selection criteria. Journal of Personality and Social Psychology, 64, 951-969.

Kenrick, D. T., \& Keefe, R. C. (1992). Age preferences in mates reflect sex differences in human reproductive strategies. Behavioral and Brain Sciences, 15, 75-133.

Kenrick, D. T., Keefe, R. C., Bryan, A., Barr, A., \& Brown, S. (1995). Age preferences and mate choice among homosexuals and heterosexuals: A case for modular psychological mechanisms. Journal of Personality and Social Psychology, 69, 1166-1172.

Kenrick, D. T., Maner, J. K., Butner, J., Li, N. P., Becker, D. V., \& Schaller (2002). Dynamic evolutionary psychology: Mapping the domains of the new interactionist paradigm. Personality and Social Psychology Review, 6, 347-356.

Kenrick, D. T., Neuberg, S. L., \& Cialdini, R. B. (2002). Social psychology: Unraveling the mystery (2nd ed.). Boston: Allyn \& Bacon.

Kenrick, D. T., Neuberg, S. L., Zierk, K. L., \& Krones, J. M. (1994). Evolution and social cognition: Contrast effects as a function of sex, dominance, and physical attractiveness. Personality and Social Psychology Bulletin, 20, 210-217.

Kenrick, D. T., Sadalla, E. K., Groth, G., \& Trost, M. R. (1990). Evolution, traits, and the stages of human courtship: Qualifying the parental investment model. Journal of Personality, 58, 97-116.

Kenrick, D. T., Sadalla, E. K., \& Keefe, R. C. (1998). Evolutionary cognitive psychology. In C. Crawford \& D. Krebs (Eds.) Handbook of evolutionary psychology (pp. 485-514). Mahwah, NJ: Erlbaum.

Kenrick, D. T., \& Trost, M. R. (1987). A biosocial model of relationship formation. In K. Kelley (Ed.), Females, males, and sexuality: Theories and research (pp. 59-100). Albany, NY: SUNY Press.

Kenrick, D. T., \& Trost, M. R. (1997). The evolutionary psychology of relationships. In S. Duck (Ed.), Handbook of personal relationships (pp. 151-177). Orlando, FL: Academic Press.

Killingback, T., \& Doebeli, M. (1996). Spatial evolutionary game theory: Hawks and Doves revisited. Proceedings of the Royal Society of London, B263, 1135-1144.

Krebs, D. L., \& Denton, K. (1997). Social illusions and self-deception: The evolution of biases in social perception. In J. A. Simpson \& D. T. Kenrick (Eds.), Evolutionary social psychology (pp. 21-48). Mahwah, NJ: Erlbaum.

Lancaster, J. B. (1976). Primate behavior and the emergence of human culture. New York: Holt.

Latané, B. (1996). Dynamic social impact: The creation of culture by communication. Journal of Communication, 46, 13-25.

Latané, B., \& Bourgeois, M. J. (1996). Experimental evidence for dynamic social impact: The emergence of subcultures in electronic groups. Journal of Communication, 46, 35-47.

Latané, B., \& L'Herrou, T. (1996). Spatial clustering in the conformity game: Dynamic social impact in electronic groups. Journal of Personality and Social Psychology, 70, 1218-1230.
Latané, B., \& Liu, J. H. (1996). The intersubjective geometry of social space. Journal of Communication, 46, 26-34.

Latané, B., \& Nowak, A. (1994). Attitudes as catastrophes: From dimensions to categories with increasing involvement. In R. R. Vallacher \& A Nowak (Eds.), Dynamical systems in social psychology (pp. 219-249). San Diego, CA: Academic Press.

Latané, B., Nowak, A., \& Liu, J. (1994). Measuring emergent social phenomena: Dynamism, polarization and clustering as order parameters of social systems. Behavioral Science, 39, 1-24.

Lewin, R. (1993). Complexity: Life at the edge of chaos. London: J. M. Dent.

Li, N. P., Bailey, J. M., Kenrick, D. T., \& Linsenmeier, J. A. (2002). The necessities and luxuries of mate preferences: Testing the tradeoffs. Journal of Personality and Social Psychology, 82, 947-955.

Lumsden, C. J., \& Wilson, E. O. (1981). Genes, mind, and culture: The coevolutionary process. Cambridge, MA: Harvard University Press.

Martindale, C. (1991). Cognitive psychology: A neural-network approach. Pacific Grove, CA: Brooks/Cole.

McWilliams, S., \& Howard, J. A. (1993). Solidarity and hierarchy in cross-sex friendships. Journal of Social Issues, 49, 191-202.

Michael, R. T., Gagnon, J. H., Laumann, E. O., \& Kolata, G. (1994). Sex in America: A definitive survey. Boston: Little Brown.

Mikach, S. M., \& Bailey, J. M. (1999). What distinguishes women with unusually high numbers of sex partners? Evolution and Human Behavior, 20, 141-150.

Miller, L. C., \& Fishkin, S. A. (1997). On the dynamics of human bonding and reproductive success: Seeking windows on the adapted-for humanenvironmental interface. In J. A. Simpson \& D. T. Kenrick (Eds.), Evolutionary social psychology (pp. 197-237). Mahwah, NJ: Erlbaum.

Moghaddam, F. M., Taylor, D. M., \& Wright, S. C. (1993). Social psychology in cross-cultural perspective. New York: Freeman.

Mook, D. G. (1983). In defense of external invalidity. American Psychologist, 38, 379-387.

Neidert, G. P., \& Linder, D. E. (1990). Avoiding social traps: Some conditions that maintain adherence to restricted consumption. Social Behaviour, 5, 261-284.

Neuberg, S. L., Smith, D., \& Asher, T. (2000). Why people stigmatize: Toward a biocultural framework. In T. F. Heatherton, R. E. Kleck, \& J. G. Hull, (Eds.), Social psychology of stigma. New York: Guilford Press.

Nowak, A., Szamrej, J., \& Latané, B. (1990). From private attitude to public opinion: A dynamic theory of social impact. Psychological Review, 97, 362-376.

Nowak, A., \& Vallacher, R. R. (1998). Dynamical social psychology. New York: Guilford.

Nowak, A., Vallacher, R. R., Tesser, A., \& Borkowski, W. (2000). Society of self: The emergence of collective properties in self-structure. Psychological Review, 107, 39-61.

Nowak, M. A., \& May, R. M. (1992, October 29). Evolutionary games and spatial chaos. Nature, 359, 826-829.

Panksepp, J. (1982). Toward a general psychobiological theory of emotions. Behavioral and Brain Sciences, 5, 407-467.

Pinker, S. (1997). How the mind works. New York: Norton.

Plutchik, R. (1980). A general psychoevolutionary theory of emotion. In R. Plutchik \& H. Kellerman (Eds.), Emotions: Theory, research, and experience (Vol. 1, pp. 3-33). New York: Academic Press.

Price, R. H., \& Bouffard, D. L. (1974). Behavioral appropriateness and situational constraint as dimensions of social behavior. Journal of Personality and Social Psychology, 30, 579-586.

Rasmussen, D. R. (1981). Pair bond strength and stability and reproductive success. Psychological Review, 88, 274-290.

Rausch, H. L. (1977). Paradox, levels, and junctures in personenvironment systems. In D. Magnusson \& N. S. Endler (Eds.), Person- 
ality at the crossroads: Current issues in interactional psychology (pp. 287-304). Hillsdale, NJ: Erlbaum.

Ridley, M. (2000). Genome: The autobiography of a species in 23 chapters. New York: HarperCollins.

Sadalla, E. K., Kenrick, D. T., \& Vershure, B. (1987). Journal of Personality and Social Psychology, 52, 730-738.

Schaller, M., \& Latané, B. (1996). Dynamic social impact and the evolution of social representations: A natural history of stereotypes. Journal of Communication, 46, 64-71.

Schelling, T. (1971). The ecology of micromotives. The Public Interest, 25, 61-98.

Schroeder, D. A. (1995). An introduction to social dilemmas. In D. A. Schroeder (Ed.), Social dilemmas: Perspectives on individuals and groups (pp. 1-14). Westport, CT: Praeger.

Schutte, N. A., Kenrick, D. T., \& Sadalla, E. K. (1985). The search for predictable settings: Situational prototypes, constraint, and behavioral variation. Journal of Personality and Social Psychology, 49, 121-128.

Scott, J. P. (1980). The functions of emotions in behavioral systems: A systems theory analysis. In R. Plutchik \& H. Kellerman (Eds.), Emotions: Theory, research, and experience (Vol. 1, pp. 35-56). New York: Academic Press.

Seligman, M. E. P., \& Hager, J. L. (1972). Biological boundaries of learning. New York: Appleton-Century-Crofts.

Sella, G., \& Lachmann, M. (2000). On the dynamic persistence of cooperation: How lower individual fitness induces higher survivability. Journal of Theoretical Biology, 206, 465-485.

Shepard, R. N. (1992). The perceptual organization of colors: An adaptation to regularities of the terrestrial world? In J. H. Barkow, L. Cosmides, \& J. Tooby (Eds.), The adapted mind (pp. 495-532). New York: Oxford University Press.

Shepher, J. (1971). Mate selection among second-generation kibbutz adolescents and adults: Incest avoidance and negative imprinting. Archives of Sexual Behavior, 1, 293-307.

Sherman, P. W. (1981). Kinship, demography, and Belding's ground squirrel nepotism. Behavioral Ecology and Sociobiology, 8, 604-606.

Sherry, D. F., \& Schacter, D. L. (1987). The evolution of multiple memory systems. Psychological Review, 94, 439-454.

Simpson, J. A., \& Gangestad, S. W. (1991). Individual differences in sociosexuality: Evidence for convergent and discriminant validity. Journal of Personality and Social Psychology, 67, 870-883.

Singh, D. (1993). Adaptive significance of female physical attractiveness: Role of waist-to-hip ratio. Journal of Personality and Social Psychology, 65, 293-307.

Snyder, M., \& Ickes, W. (1985). Personality and social behavior. In G. Lindzey \& E. Aronson (Eds.), Handbook of social psychology (Vol. 2, 3rd ed., pp. 883-848). New York: Random House.

Stevens, L. E., \& Fiske, S. T. (1995). Motivation and cognition in social life: A social survival perspective. Social Cognition, 13, 189-214.

Symons, D. (1979). The evolution of human sexuality. New York: Oxford.

Symons, D. (1992). On the use and misuse of Darwinism in the study of human behavior. In J. H. Barkow, L. Cosmides, \& J. Tooby (Eds.), The adapted mind (pp. 137-159). New York: Oxford University Press.

Tesser, A., \& Achee, J. (1994). Aggression, love, conformity, and other social psychological catastrophes. In R. R. Vallacher \& A. Nowak
(Eds.), Dynamical systems in social psychology (pp. 96-109). San Diego, CA: Academic Press.

Tooby, J., \& Cosmides, L. (1990). On the universality of human nature and the uniqueness of the individual: The role of genetics and adaptation. Journal of Personality, 58, 17-67.

Tooby, J., \& Cosmides, L. (1992). The psychological foundations of culture. In J. H. Barkow, L. Cosmides, \& J. Tooby (Eds.), The adapted mind (pp. 19-136). New York: Oxford University Press.

Townsend, J. M. (1992). Measuring the magnitude of sex differences. Behavioral and Brain Sciences, 15, 115.

Trivers, R. L. (1971). The evolution of reciprocal altruism. Quarterly Review of Biology, 46, 35-57.

Trivers, R. L. (1972). Parental investment and sexual selection. In B. Campbell (Ed.), Sexual selection and the descent of man, 1871-1971 (pp. 136-179). Chicago: Aldine.

Trivers, R. L. (1974). Parent-offspring conflict. American Zoologist, 14, 249-264.

U.S. Census Bureau. (2000). Marriage and divorce data. Washington, DC: U.S. Department of Commerce.

van Gelder, T. (1998). The dynamical hypothesis in cognitive science. Behavioral and Brain Sciences, 21, 615-666.

Waldrop, M. M. (1992). Complexity: The emerging science at the edge of order and chaos. New York: Touchstone.

Weiner, J. (1999). Time, love, memory: A great biologist and his quest for the origins of behavior. New York: Knopf.

White, G. M. (1980). Conceptual universals in interpersonal language. American Anthropologist, 82, 759-781.

Wiggins, J. S., \& Broughton, R. (1985). The interpersonal circle: A structural model for the integration of personality research. In R. Hogan \& W. H. Jones (Eds.), Perspectives in personality (Vol. 1, pp. 1-48). Greenwich, CT: JAI Press.

Wilcoxon, H., Dragoin, E., \& Kral, P. (1971, February 26). Illness-induced aversions in rats and quail: Relative salience of visual and gustatory cues. Science, 171, 826-828.

Wilkinson, G. S. (1988). Reciprocal altruism in bats and other mammals. Ethology and Sociobiology, 9, 85-100.

Wilkinson, G. S. (1990). Food sharing in vampire bats. Scientific American, 262, 76-82.

Wilson, D. S. (1997). Incorporating group selection into the adaptationist program: A case study involving human decision making. In J. A. Simpson \& D. T. Kenrick (Eds.), Evolutionary social psychology (pp. 345-386). Mahwah, NJ: Erlbaum.

Wilson, E. O. (1975). Sociobiology: The new synthesis. Cambridge, MA: Harvard University Press.

Wilson, E. O. (1992). The diversity of life. New York: Norton.

Wilson, E. O. (1998). Consilience: The unity of knowledge. New York: Knopf.

Wolfram, S. (1986). Theory and applications of cellular automata. Singapore: World Scientific.

Zeeman, E. C. (1976). Catastrophe theory. Scientific American, 4, 65-70, $75-83$.

Received April 25, 2000

Revision received October 16, 2001

Accepted November 30, 2001 